\title{
LA-UR-16-27168
}

Approved for public release; distribution is unlimited.

Title: $\quad$ Lifetime Extension Report: Progress on the SAVY-4000 Lifetime Extension Program

Author(s): $\quad$ Weis, Eric; Welch, Cynthia F.; Smith, Paul Herrick; Blair, Michael W.; Stone, Timothy Amos; Veirs, Douglas Kirk; Reeves, Kirk Patrick; Karns, Tristan; Oka, Jude M.; Keller, Jennie; Meincke, Linda Jeanne; Torres, Joseph Angelo; Herman, Matthew Joseph; Weaver, Brian Phillip; Adams, Jillian Cathleen; Trautschold, Olivia Carol

Intended for: Report

Issued: 2016-11-17 (rev.2) 
Disclaimer:

Los Alamos National Laboratory, an affirmative action/equal opportunity employer, is operated by the Los Alamos National Security, LLC for the National Nuclear Security Administration of the U.S. Department of Energy under contract DE-AC52-06NA25396. By approving this article, the publisher recognizes that the U.S. Government retains nonexclusive, royalty-free license to publish or reproduce the published form of this contribution, or to allow others to do so, for U.S. Government purposes. Los Alamos National Laboratory requests that the publisher identify this article as work performed under the auspices of the U.S. Department of Energy. Los Alamos National Laboratory strongly supports academic freedom and a researcher's right to publish; as an institution, however, the Laboratory does not endorse the viewpoint of a publication or guarantee its technical correctness. 


\section{Lifetime Extension Report Progress on the SAVY-4000 Lifetime Extension Program}

\author{
Eric M. Weis (MST-7) \\ Cynthia F. Welch (MST-7) \\ Paul H. Smith (NPI-2) \\ Michael W. Blair (MST-7) \\ Tim A. Stone (NPI-2) \\ D. Kirk Veirs (MET-1) \\ Kirk P. Reeves (NPI-2) \\ Tristan Karns (NPI-2)
}

\author{
Jude M. Oka (NPI-2) \\ Jennie Keller (MST-7) \\ Linda Meincke (MST-7) \\ Joseph A. Torres (MST-7) \\ Matthew J. Herman (MST-7) \\ Brian Weaver (CCS-6) \\ Jillian C. Adams (MST-7) \\ Olivia C. Trautschold (MST-7)
}

\section{Executive Summary}

The 3-year accelerated aging study of the SAVY-4000 O-ring shows very little evidence of significant degradation to samples subjected to aggressive elevated temperature and radiation conditions. Whole container thermal aging studies followed by helium leakage testing and compression set measurements were used to establish an estimate for a failure criterion for Oring compression set of $\geq 65 \%$. The thermal aging data for O-ring compression set do not meet the assumptions of standard time-temperature superposition analysis for accelerated aging studies. Instead, the data suggest that multiple degradation mechanisms are operative, with a reversible mechanism operative at low aging temperatures and an irreversible mechanism dominating at high aging temperatures. To distinguish between these mechanisms, we have measured compression set after allowing the samples to physically relax, thereby minimizing the effect of the reversible mechanism. The resulting data were analyzed using two distinct mathematical methods to obtain a lifetime estimate based on irreversible degradation alone. Both methods support a lifetime estimate of greater than 65 years at $80^{\circ} \mathrm{C}$. Although the role of the reversible mechanism is not fully understood, it is clear that the contribution to the total compression set is small in comparison to that due to the irreversible degradation mechanism. To better understand the irreversible degradation mechanism, thermally aged O-ring samples have been characterized by Fourier Transform Infrared (FTIR), Electron Paramagnetic Resonance (EPR), Gel Permeation Chromatography (GPC), and Differential Scanning Calorimetry (DSC). These experiments detect no significant O-ring degradation below $80^{\circ} \mathrm{C}$. Furthermore, durometer measurements indicate that there is no significant change in O-ring hardness at all aging conditions examined. Therefore, our results fully support the proposed lifetime extension for the O-ring to 40 years at $80^{\circ} \mathrm{C}$. In FY17, we will continue to probe irreversible degradation mechanisms using oxygen consumption measurements under accelerated aging conditions to reveal temperatures at which oxidation occurs, along with any differences in oxidation rate at the low vs. high aging temperatures. We will also refine the failure criteria, finalize the radiation/thermal synergistic studies, and continue to gather and analyze data from the surveillance program to assess any issues that might challenge this design lifetime. 


\section{Introduction}

The Department of Energy (DOE) issued DOE M 441.1-1, Nuclear Material Packaging Manual, in March 2008, to protect workers who handle nuclear material from exposure due to loss of containment of stored materials. ${ }^{1}$ The manual specifies a detailed approach to achieve high confidence in containers and includes requirements for container design and performance, design-life determinations, material contents, and surveillance and maintenance to ensure container integrity over time. The materials considered within the scope of the manual include actinides stored outside an approved engineered-contamination barrier that could result in a worker exposure of greater than 5 rem Committed Effective Dose Equivalent (CEDE) if containment is lost.

In order to implement DOE M441.1-1, Nuclear Filter Technology, Inc. (NucFil) and LANL developed the SAVY-4000 container, named for the designers Stone, Anderson, Veirs, and Yarbro. ${ }^{2}$ The SAVY-4000 design includes eight sizes (1-, 2-, 3-, 5-, 8-, 12-quart and 5- and 10gallon) and they will replace the current "Hagan" style containers ${ }^{3}$ of the same sizes. The SAVY4000 is closed and sealed by pushing the lid downward into the collar resulting in radial compression of an O-ring between the body collar and a piston groove in the lid, as shown in Figure 1.

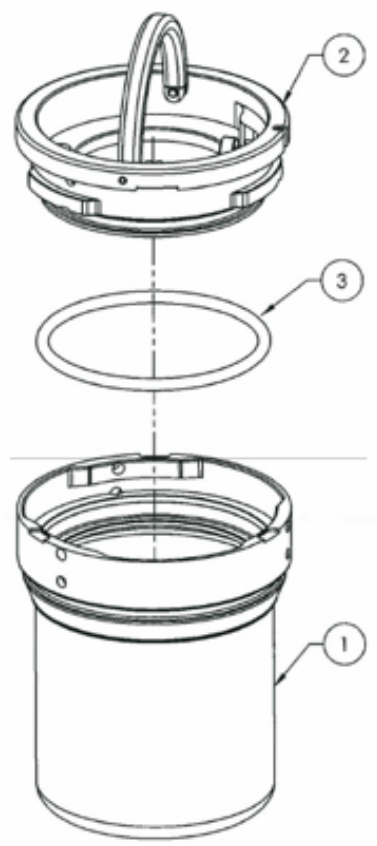

(a)

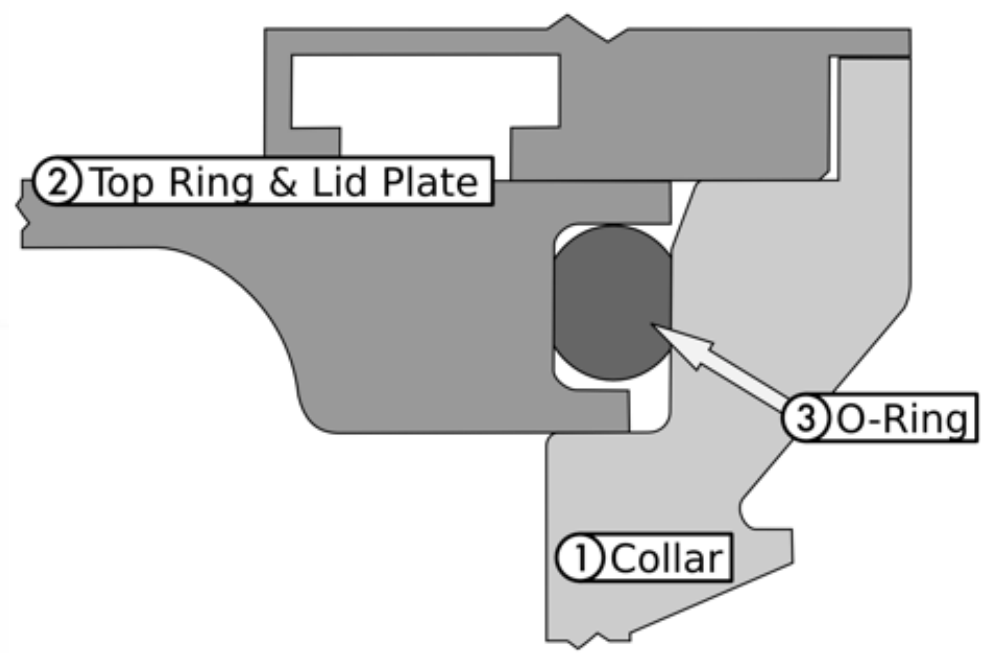

(b)

Figure 1. (a) SAVY-4000 container, showing (a2) the lid plate and top ring, (a3) Oring, and (a1) container body with collar. (b) cross-sectional view of the O-ring installed in the lid in a closed container.

The O-ring used in the SAVY-4000 has been identified as one of the lifetime-limiting components of the design, and it is a part that is vulnerable to wear through repeated use. Preliminary studies detailed ${ }^{4,5}$ the basic properties, composition and durability of the SAVY4000 O-rings. However, the fluoropolymer-based O-ring may deteriorate over time due to 
compression, elevated temperatures, and exposure to ionizing radiation. Our O-rings are a type of FKM rubber (like Viton ${ }^{\circledR}$ ) purchased from Parker, Inc. In personal communication, a Parker quality control scientist further specified that the base polymer was a copolymer of hexafluoropropene (HFP) and vinylidene difluoride (VDF), which is known as Type 1 FKM.

In 2013, we developed an accelerated aging $\operatorname{plan}^{6}$ to quantify changes, both chemical and physical, that the O-ring could display as a result of service conditions. The current report details the current results of accelerated aging experiments (Sections 3-4). Current conclusions regarding lifetime, along with future work aimed at addressing uncertainties in that lifetime, are contained in Section 5. 


\section{Experimental}

\subsection{Mechanical Testing}

\subsubsection{Compression Set}

Compression set measurements were conducted as per method B as described in the ASTM standard. ${ }^{7}$ Three $\sim 2.5 \mathrm{~cm}$ pieces of O-ring were each measured for thickness using a Mitutoyo Litematic light-touch indicator, or a Beta Lasermike Z-Mike. The average of three measurements was taken as the thickness of each piece. The pieces were held compressed between chromiumfinished plates between two 1/4" steel plates, held in place by three bolts. The compression jigs were heated in their respective ovens for at least two hours before the samples were loaded. The samples were quickly placed in the jig, the bolts were tightened and the jigs were returned to the ovens.

After the specified aging time had elapsed, the jigs were removed from the ovens, the bolts were loosened, and the three aged O-ring pieces were pushed from the jig onto a wooden surface. After the pieces had cooled for no less than 30 minutes, the thickness of each piece was measured. The average of three measurements was taken as the thickness of the piece. The amount of compression set for one sample was computed as

$$
C_{\mathrm{B}}=\frac{t_{0}-t_{i}}{t_{0}-t_{n}} \times 100 \%
$$

where $C_{\mathrm{B}}$ is the method-B compression set, $t_{0}$ is the original thickness, $t_{i}$ is the final thickness, and $t_{n}$ is the thickness of the spacer between the plates of the jig. The compression set for a specific time and temperature combination is the median of the three sample values.

The thickness of the O-ring segments was again measured after some time had passed, between two years and two weeks, depending on the sample. The compression set value was recomputed, with an adjusted initial measurement to reflect the difference in measurement technique between the Litematic and the Lasermike. Elastomers measured with the Litematic deform under the pressure of the probe, but the Lasermike causes no deformation.

\subsubsection{Durometry}

The hardness of each O-ring was measured as described in the ASTM standard for durometry. ${ }^{8}$ Our durometer is a Shore-M model 100 durometer, with a digital readout and hydraulic descent control. A stage extender was utilized with whole O-rings to make sure they could lie flat during measurement.

\subsection{Spectroscopic Characterization}

Mechanical and thermal property testing is often sufficient to establish a predicted lifetime given certain conditions and failure criteria for a material. However, these properties do not lead to an understanding of the underlying physical and chemical changes that produce degradation. By studying spectroscopic signatures, mechanical properties, and thermal properties of polymers in an accelerated aging program simultaneously, we hope to directly link changes in the bulk properties to microscopic changes and increase the understanding of material properties. 


\subsubsection{Infrared Spectroscopy}

The infrared absorption spectrum was taken for each sample using the diamond crystal ATR attachment for a Bruker Vertex 80V FT-IR under vacuum. Each spectrum was intensitystandardized against the NIST infrared transmission standard 1921b. The FTIR spectra were analyzed and compared with one another though the $R$ software package ChemoSpec. ${ }^{9}$

To make assignments of a chemical identity to each peak in the IR spectrum, a computational study was done on a model intended to represent the polymer used in V0986-50. The computation was performed in Gaussian ' $09,{ }^{10}$ with the $3-21 g$ basis set and the pbepbe functional on a model constructed to represent typical FKM polymer strands. ${ }^{11,12,13}$

\subsubsection{Electron Paramagnetic Resonance (EPR)}

The EPR spectrum of each sample was taken twice, once in the normal range from 0 to 700 Gauss, and again in an extended range from 0 to 6000 Gauss. Taking the spectra again in the extended range allows for the detection of metals not seen in the normal range. The intensity of each spectrum was normalized to a range of +1 to -1 , and the $g$-factor for the primary transition in each spectrum was determined as the point where the trace crossed from negative values to positive.

\subsubsection{Differential Scanning Calorimetry (DSC)}

Differential scanning calorimetry was performed on a TA Q2000. Enthalpy and temperature calibrations were performed with sapphire and indium standards before experiments were performed. Dry nitrogen was flowed through the sample cell at a rate of $50 \mathrm{ml} / \mathrm{min}$. Approximately $20 \mathrm{mg}$ cut from a single O-ring piece was placed in a hermetically sealed aluminum pan for each experiment.

The temperature of each sample was allowed to equilibrate at $0^{\circ} \mathrm{C}$, ramped at $50^{\circ} \mathrm{C} / \mathrm{min}$ to $300^{\circ} \mathrm{C}$, cooled to $0^{\circ} \mathrm{C}$ at $20^{\circ} \mathrm{C} / \mathrm{min}$, and then ramped to $300^{\circ} \mathrm{C}$ at $50^{\circ} \mathrm{C} / \mathrm{min}$ again.

\subsubsection{Gel Permeation Chromatography (GPC)}

Analysis was performed with a Waters ${ }^{\circledR}$ GPC system, consisting of an Alliance 2690 pump, a Waters 996 photodiode array (PDA) detector, and a PLgel mixed E column $(3.6 \mathrm{~mm} \varnothing \times 250 \mathrm{~mm}$ length, Agilent). The column temperature was $40^{\circ} \mathrm{C}$. The injection volume was $30 \mu \mathrm{L}$, and the effluent flow rate was $0.3 \mathrm{~mL} / \mathrm{min}$. Tetrahydrofuran (THF) (Aldrich, HPLC grade, without BHT) was used as a mobile phase. The monitoring range of the PDA detector was set to $190-500 \mathrm{~nm}$. One polystyrene standard tap containing 5 narrow polystyrene (PS) standards (Agilent, EasiCal PS2B), with molecular weights ranging from 0.580 to $210 \mathrm{~kg} / \mathrm{mol}$, was used to calibrate the detector. Empower 2 software was used to retrieve the GPC results and UV-Vis spectra.

To prepare GPC solutions, $\sim 20 \mathrm{mg}$ of aged samples were sliced into small pieces and soaked in $10 \mathrm{ml}$ of anhydrous $\mathrm{THF}$ at room temperature or at $50^{\circ} \mathrm{C}$. Prior to the injection, the sample solution was filtered through a $0.45 \mu \mathrm{m}$ PFTE filter.

\subsection{Whole-Container Aging}

O-rings were installed in 1-Quart SAVY containers and each was placed in an aging oven at a temperature of $70,90,120,160$, or $210^{\circ} \mathrm{C}$. Periodically, over the course of nine months, the cans 
were withdrawn from the ovens and allowed to cool to room temperature for leak testing. The leak rate of a SAVY-4000 container with the sample O-ring installed was measured using a LACO Flexstation ${ }^{\mathrm{TM}}$ bell-jar helium mass-spectroscopy leak tester. The leak tester detects the presence of a leak, defined as a rate higher than $1 \times 10^{-5} \mathrm{~atm} \mathrm{~cm}^{3} \mathrm{~s}^{-1}$, by analyzing the atmosphere for helium in a bell jar held near vacuum, when the container in the bell jar is charged with 75 torr of helium. The leak test is the only defined failure criteria for the O-ring in a SAVY-4000 container. The containers were then returned to the oven for further aging.

Lids were removed and tested for filter degradation at the end of the whole-container study. The particle penetration test used an aerosol of PAO (poly-alpha olefin) with a concentration of 65 $\pm 15 \mu \mathrm{g} / \mathrm{L}$ upstream of the filter. The concentration was measured using an ATI $2 \mathrm{H}$ photometer, which was modified by the manufacturer for the test flow-rate of $200 \mathrm{cc} / \mathrm{min}$.

Filter performance was measured using Filter Test System for Nuclear Container Filters. ${ }^{15}$ A total of nine SAVY -4000 lids were tested for filter performance. Five of the lids were aged at varying temperature $\left(70,90,120,160\right.$ and $\left.210^{\circ} \mathrm{C}\right)$ for a duration of 293 days, and the remaining four lids were all aged at a temperature of $210^{\circ} \mathrm{C}$ for a duration of 116 days. After the aging was complete, the lids were allowed to cool to room temperature for testing. The lids were tested for filter efficiency and the pressure drop across the filters.

The pressure drop testing was done at the same time as the aerosol testing. When the instrument was switched to measure the downstream filter concentration, the data system recorded 15 pressure drop data values, at one-second intervals. The first two data points were discarded, since there is a momentary spike in the system pressure during switching. The average of the remaining 13 is reported.

Water penetration was measured using a sealed system that allows air pressure to be applied to a column of water so that the desired water pressure can be reached. A mechanical fixture with an O-ring seal attached to the four threaded holes in the filter portion of the SAVY-4000 lid was used in conjunction with a measurable water column to test the water resistance function. The same nine aged lids used in the Filter Performance section of this report were also used in the water penetration tests. The water penetration test was performed after the filter performance test. The failure criteria for the water penetration test is the visual appearance of water at the lower surface of the filter when exposed to a 12 inch water column for a dwell time of one minute. 


\section{$4 \quad$ Results}

\subsection{Spectroscopic Baseline Study}

\subsubsection{Infrared Spectroscopy}

We have made tentative assignments to the chemical identities of the bands in the IR spectra based on calculated spectra for the monomers used in this polymer. Our O-rings are purchased from Parker, Inc, as made from compound V0896-50, their proprietary formulation of an FKM rubber ${ }^{9}$. In personal communication, a Parker quality control scientist further specified that the base polymer was a copolymer of hexafluoropropene (HFP) and vinylidene difluoride (VDF), and that the crosslinking agent used was a bisphenol. The HFP-VDF copolymer is consistent with what is known as Type 1 FKM. Parker, Inc, also claims that these O-rings are chemically resistant; thus, the bisphenol crosslinking agent is likely bisphenol-AF (BPAF), in which the terminal methyl groups are perfluorinated. These organic molecules are shown in Figure 2.

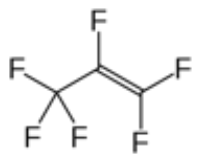

(a)<smiles>FC=CF</smiles>

(b)

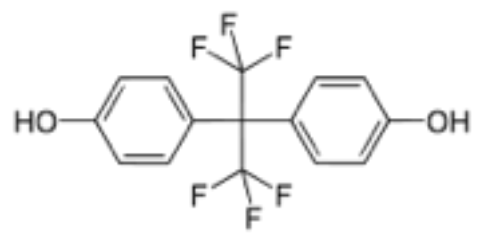

(c)

Figure 2. SAVY-4000 O-rings are made of a commercial FKM rubber, which is made from monomers (a) hexafluoropropene, and (b) vinylidene difluoride. The resulting polymer is crosslinked in this formulation with (c) bisphenol-AF.

We can analyze the spectra obtained from our baseline samples, that is, samples of O-ring that have not been aged at an elevated temperature nor exposed to radiation, in terms of the contributions the spectra of the monomers make to the whole. The spectra for each monomer and the composite spectrum of the three components are shown in Figure 3. 


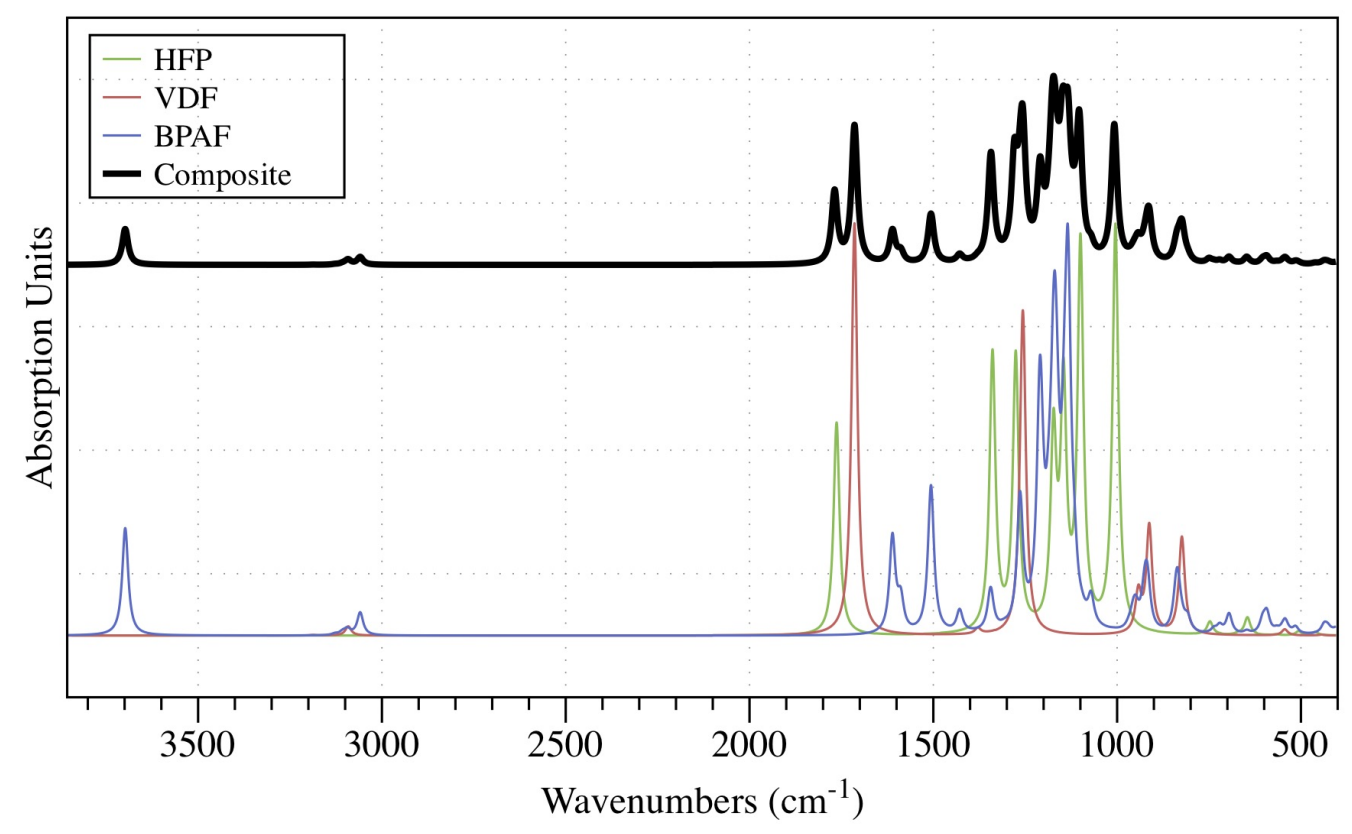

Figure 3. Calculated spectra of the monomers used in cured FKM polymer, shown in color, and the composite spectrum of the three, shown in bold black.

We also completed computations on a model segment of the suspected FKM polymer. The computation was performed in Gaussian '09, with the 3-21g basis set and the pbepbe functional. From the model molecule, the frequency calculation calculated the vibrational modes of the molecule, and the change in dipole associated with those vibrations. This gave a list of the expected IR absorption frequencies, with the molecular motions responsible for each. These modes are indicated in Figure 4b.

A comparison between the computed and measured spectra shows the chemistry that has occurred on polymerization. The largest feature of the measured spectra is the pair of peaks at 1173 and 1132, and they have been assigned to motions of the $\mathrm{CH}_{2}$ group from VDF coupled to motions of the $\mathrm{CF}_{3}$ group from HFP. These peaks are absent from the monomers, because in the monomers, there are no $\mathrm{CH}_{2} \Leftrightarrow \mathrm{CF}_{3}$ couplings possible. There are many peaks due to motions of the carbon-carbon double bond in the computed spectra, but they are absent from the measured spectra, indicating the complete polymerization of the starting monomers, and no, or very few, $\mathrm{C}=\mathrm{C}$ bonds present in the finished product. These assignments are consistent with previous research ${ }^{10}$. The expected peaks from the bisphenol crosslinking agent are absent from the measured spectra as well, but it may be that the concentration of the bisphenol-AF is very low compared to the polymer; lower than the threshold of detection in this IR technique. 

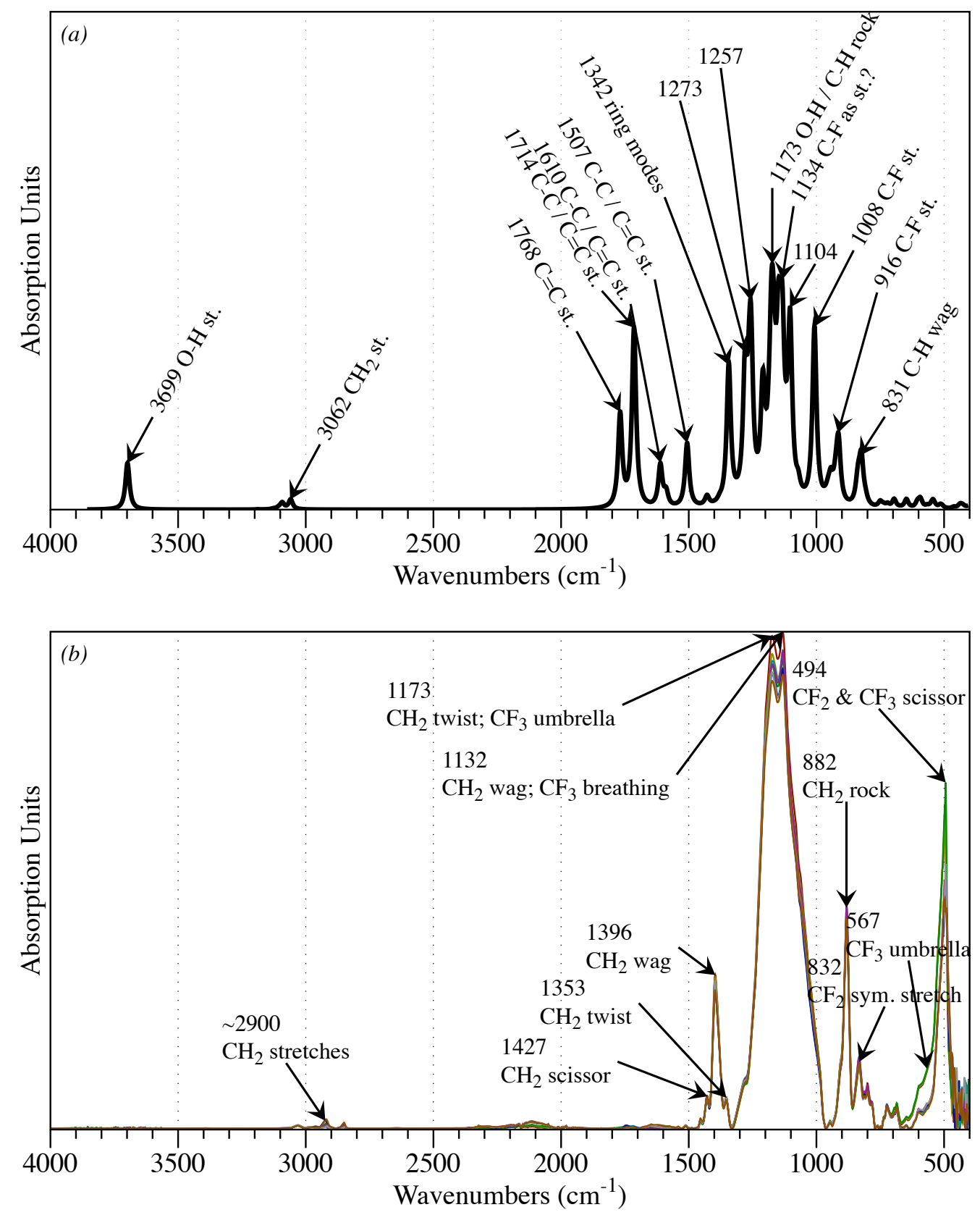

Figure 4. (a) The composite spectrum of the two monomers and the crosslinking agent with indications of the chemical functional group responsible for each peak. (b) Infrared spectra overlaid together for all unaged samples with indications of the vibrational mode responsible for each peak.

\subsubsection{Elemental Analysis}

Elemental analysis was performed by calibrated EDAX, with a rhodium X-ray source, shown in Table 1. 


\section{Table 1. Weight-percent composition of SAVY O-rings, for elements that are apparent under $\mathrm{X}$-ray fluorescence, assuming metals are present in oxide forms.}

\begin{tabular}{c|c|c} 
Element & $\begin{array}{c}\text { Assumed } \\
\text { Compound }\end{array}$ & $\mathbf{W t \%}$ of O-ring \\
\hline $\mathbf{M g}$ & $\mathrm{MgO}$ & 2.5 \\
$\mathbf{S i}$ & $\mathrm{SiO}_{2}$ & 3.6 \\
$\mathbf{S}$ & $\mathrm{S}$ & 0.10 \\
$\mathbf{C a}$ & $\mathrm{CaO}$ & 4.8 \\
$\mathbf{F e}$ & $\mathrm{Fe}_{2} \mathrm{O}_{3}$ & 3.2
\end{tabular}

This is important to the lifetime assessment because certain metals, such as magnesium and calcium, can act as fluoride getters. As the O-ring is irradiated, it will act as a source of fluoride ions. These could react with the $\mathrm{Ca} / \mathrm{Mg}$ species present in the O-ring to form $\mathrm{Ca} / \mathrm{Mg}$ fluoride, preventing the fluoride ion from reacting with the polymer, or migrating out of the O-ring to react with the sealing surface.

\subsection{Whole-Container Aging Study}

In order to correlate a leak rate failure with other diagnostic tests, O-rings were installed in 1Quart SAVY containers that were then placed in the aging ovens. Leak tests, as described in Section 3.1.1, were conducted with a frequency of between 2 weeks and 6 months during a 9month period. The containers passed each leak test conducted immediately after oven storage, as shown in Table 2.

The container kept at $210^{\circ} \mathrm{C}$ was particularly difficult to open, and extra leverage from a screwdriver was needed to pry the lid from the collar. There was some discoloration of the gland in the collar of the SAVY-the sealing surface had become somewhat darker-but the O-ring remained intact, and there was no residue left behind. The O-ring was cleaned, greased, reinstalled in the can and tested again, and it failed the leak test. Two weeks later, it was again leak-tested and it failed again.

The compression set was estimated for each of the O-ring in this experiment. The initial thickness was assumed to be the nominal O-ring thickness with the uncertainty taken as the manufacturer's tolerance, $0.210 \pm 0.005$ inches. The compression thickness was taken as the nominal gland depth and tolerance from the SAVY-4000 1-Qt engineering drawings, $0.170 \pm$ 0.003 inches. The thickness of each O-ring was measured with the LaserMike laser micrometer, as the average of eight measurements from around the O-ring. The $210^{\circ} \mathrm{C}$ O-ring was remeasured and leak tested again after two weeks, and found to fail the leak test and have maintained a compression set. Since the $210^{\circ} \mathrm{C}$ O-ring maintained a compression set of up to 88 $\pm 20 \%$ for at least two weeks, and still failed a leak test, the compression set limit should be conservatively set to $65 \%$ for other aging determinations. 
Table 2. Estimated compression set and leak test result of the wholecontainer aged O-rings.

\begin{tabular}{c|lccc} 
Aging Temperature & Compression Set & $\begin{array}{c}\text { Leak Test } \\
\text { Result } \\
\text { Before } \\
\text { ring } \\
\text { Removal }\end{array}$ & $\begin{array}{c}\text { Leak Test } \\
\text { Result } \\
\text { Immediately } \\
\text { After O-ring } \\
\text { Removal }\end{array}$ & $\begin{array}{c}\text { Leak Test after } \\
\text { O-ring } \\
\text { Relaxation }\end{array}$ \\
\hline $\mathbf{2 1 0}^{\circ} \mathbf{C}$ & $93 \% \pm 19 \%$ & Pass & Fail & Fail \\
$\mathbf{1 6 0}^{\circ} \mathbf{C}$ & $13 \% \pm 20 \%$ & Pass & Pass & NA \\
$\mathbf{1 2 0}^{\circ} \mathbf{C}$ & $36 \% \pm 14 \%$ & Pass & Pass & NA \\
$\mathbf{9 0}^{\circ} \mathbf{C}$ & $18 \% \pm 13 \%$ & Pass & Pass & NA \\
$\mathbf{7 0}^{\circ} \mathbf{C}$ & $21 \% \pm 8 \%$ & Pass & Pass & NA
\end{tabular}

\subsubsection{Durometer}

The hardness of each O-ring used in the whole-container aging experiments was measured twice, once in the direction of compression of the O-ring in the assembled container, along its equator, and once in the axial direction (Figure 5). When the standard error from ASTM D395 (shown as red lines) is considered, there is no detectable change in the durometer for these samples.

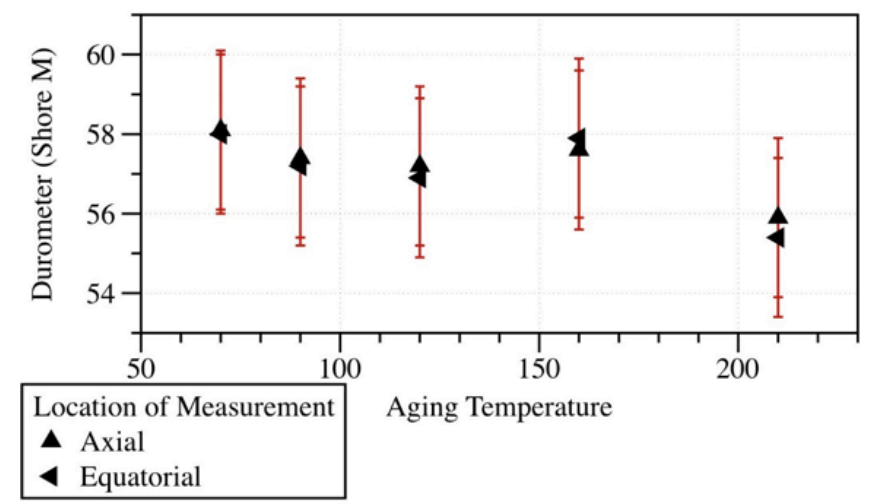

Figure 5. Hardness versus aging temperature for O-rings aged in SAVY containers.

\subsubsection{Filter Performance}

The filter is made up of two components that are built into the SAVY lid. A ceramic fiber layer provides the filter function, and a porous PTFE membrane that is mounted above the ceramic fiber layer provides the water resistant function. The filter function was assessed after subjecting whole SAVY containers to thermal aging, and it was compared to the function at the time of manufacture; results are illustrated in Figures 6 and 7. There was no apparent change or trend in filtration efficiency (\% penetration) before and after aging, and the filters all pass the criteria of capturing $99.97 \%$ of the challenge aerosol after thermal aging. For $\%$ penetration, the average and standard deviation for the four filters in Batch 2 (aged at $210^{\circ} \mathrm{C}$ for four months) after aging were 0.0007 , and 0.0003 respectively. This compares to a set of 10 standard filters with $\%$ penetration, average $=0.0006$ and $\mathrm{SD}=0.0004$. It is noteworthy that the measured efficiencies 
for all aged filters are always at least a factor of 10 lower than the failure criteria of 0.03 . For pressure drop, the average and standard deviation for the four filters in Batch 2 after aging were 0.4 , and 0.02 (inches WC) respectively. Based on this limited data, it appears that this is a significant change. This compares to a set of 10 standard filters with average $=0.79$ and $\mathrm{SD}=0.04$ (inches WC). The water penetration testing indicates that the water resistant function can degrade enough to cause water penetration failure after aging at temperatures above $160^{\circ} \mathrm{C}$. The passing criteria for this test is no visible water penetration after 1 minute at 12 inches WC. The pressure drop data combined with the water penetration pass/fail results suggests that a decrease in pressure drop across the filter may be associated with degradation in water resistance. This may allow the use of pressure drop measurement as a leading indicator of membrane failure, but this remains to be confirmed based on further surveillance and experimental testing. Although these results do not serve to predict a filter lifetime, it is noteworthy that we have not observed significant filtration efficiency, pressure drop or water resistance degradation after aging below the maximum normal operating temperature of the PTFE membrane $\left(130^{\circ} \mathrm{C}\right)$. (The inconsistency of the filter that was aged at $210^{\circ} \mathrm{C}$ for 10 months passing the water penetration test and the filter that was aged at the same temperature for four months failing that test is noted, and needs to be confirmed.)

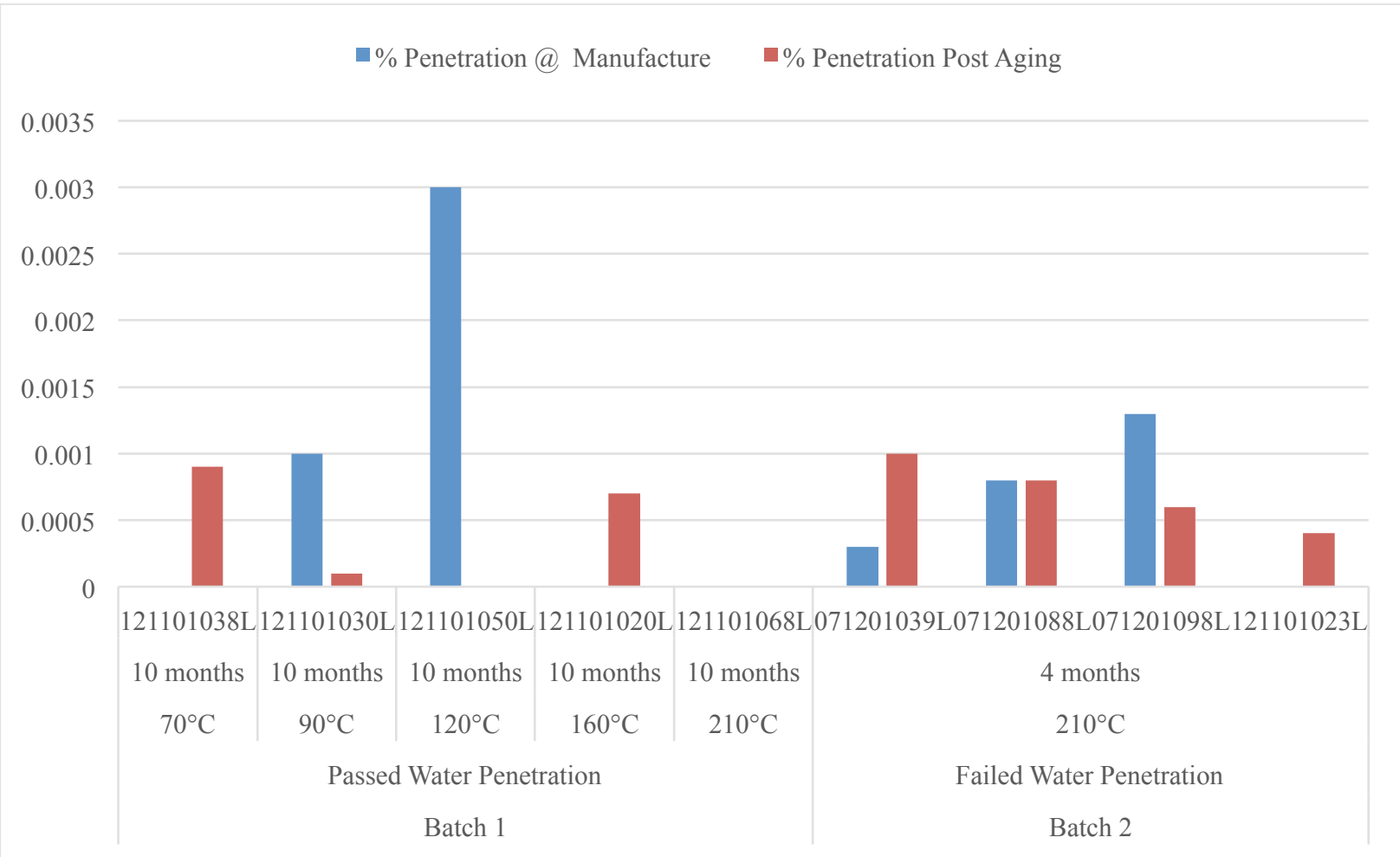

Figure 6. Filter efficiency and water penetration test results for filters measured at manufacture and after high temperature aging. 


\section{- Pressure Drop@ Manufacture घ Pressure Drop Post Aging}

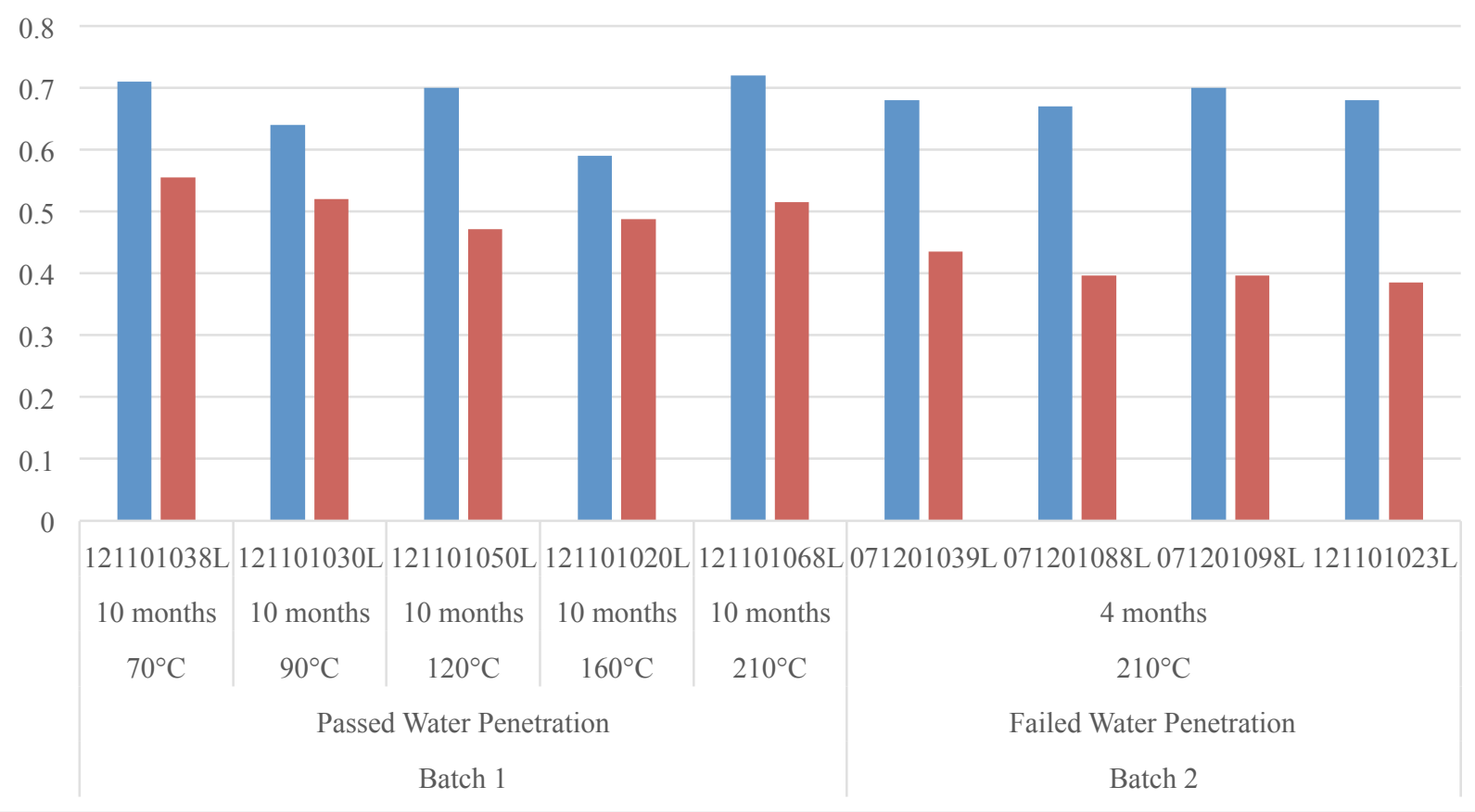

Figure 7. Pressure drop and water penetration test results for filters measured at manufacture and after high temperature aging.

\subsection{Thermal Aging Study}

\subsubsection{Compression Set}

Compression set measurements for O-ring pieces aged under compression at temperatures between $70-210^{\circ} \mathrm{C}$ are shown in Figure 8a. Recall that for each aging condition, three O-ring pieces were measured; in Figure 8, results for each replicate are shown. The horizontal line at a compression set of 0.65 (or 65\%) marks the failure criterion established by the whole container aging results described above. Only a small number of samples in the accelerated aging study show compression set values above this line, and those were aged at the highest temperatures $\left(190\right.$ and $\left.210^{\circ} \mathrm{C}\right)$. However, the data appear to follow at least two different trends, suggesting that at least two processes leading to compression set are operative. One of these processes dominates at low aging temperatures, while the other dominates at high temperatures. Careful inspection of the low temperature data shows that compression set appears to vary inversely with temperature, which is opposite to expectations for a chemical process. Thus, this is likely a physical mechanism, which should be reversible. At high aging temperatures, the second mechanism follows the expected temperature dependence and is likely chemical and irreversible in nature. Because of this behavior, time-temperature superposition cannot be applied to the data shown in Figure 8a. In addition, to more accurately estimate a lifetime of the O-ring, the effects of the reversible process need to be separated from those of any irreversible processes. A reversible process should not reduce the ability of the O-ring to maintain a proper seal, while irreversible processes could. 

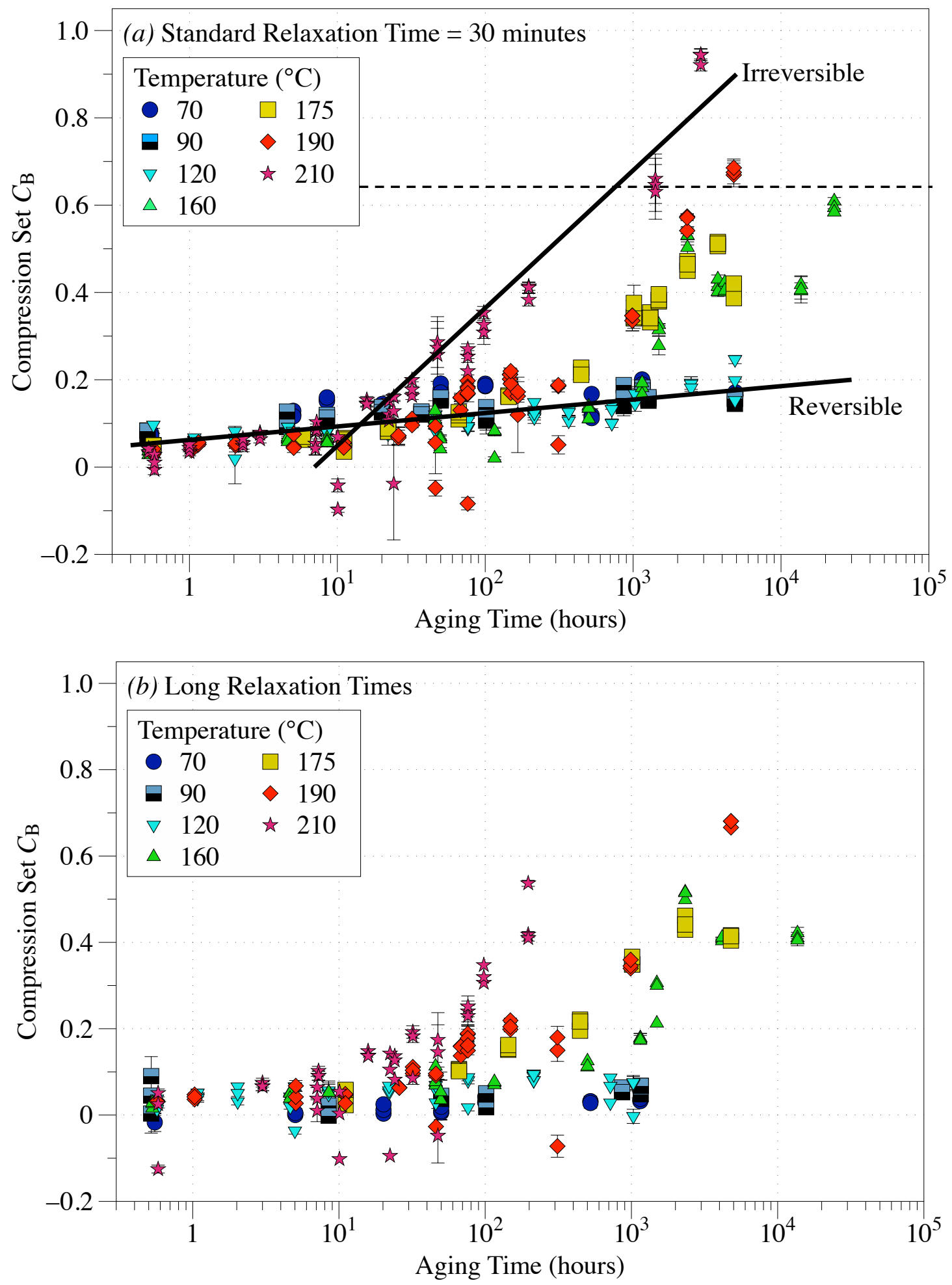

Figure 8. Showing all data points (i.e., replicates) from each experiment. (a) Initial compression set of O-ring pieces from accelerated aging experiments. (b) Compression set of the same samples shown in (a), but measured after the reversible compression has relaxed further. 
To separate the effects of any reversible (e.g., physical) mechanisms from any irreversible (e.g., chemical) ones, we took a second measurement of compression set of each sample, several thousand hours after their first measurement. These data, shown in Figure 8b, should represent compression set induced only by irreversible mechanisms. This is a subset of the samples shown in Figure 8a, as a number of the samples were destroyed for other analyses, or were too "young" after the standard compression set experiment to be of use for this writing. Figure 9 compares the median values for standard compression set (i.e., from Figure 8a) to those for relaxed compression set (i.e., from Figure $8 \mathrm{~b}$ ). In this plot, data points that fall on the $\mathrm{y}=\mathrm{x}$ line (shown in gray) represent samples that maintain their initial compression set values when measured several thousand hours later; this is largely the case for samples aged at high temperatures ( $\geq$ $\left.160^{\circ} \mathrm{C}\right)$. On the other hand, samples aged at low temperatures $\left(70-120^{\circ} \mathrm{C}\right)$ show a reduction in compression set after relaxation; this confirms that a reversible process dominates the low temperature compression set data in Figure 8a. In the coming months, we will continue to investigate compression set relaxation in samples that appear in Figure 8a but not in Figure 8b. In addition, we will conduct a set of experiments aimed at understanding the rate of compression set relaxation at low aging temperatures.

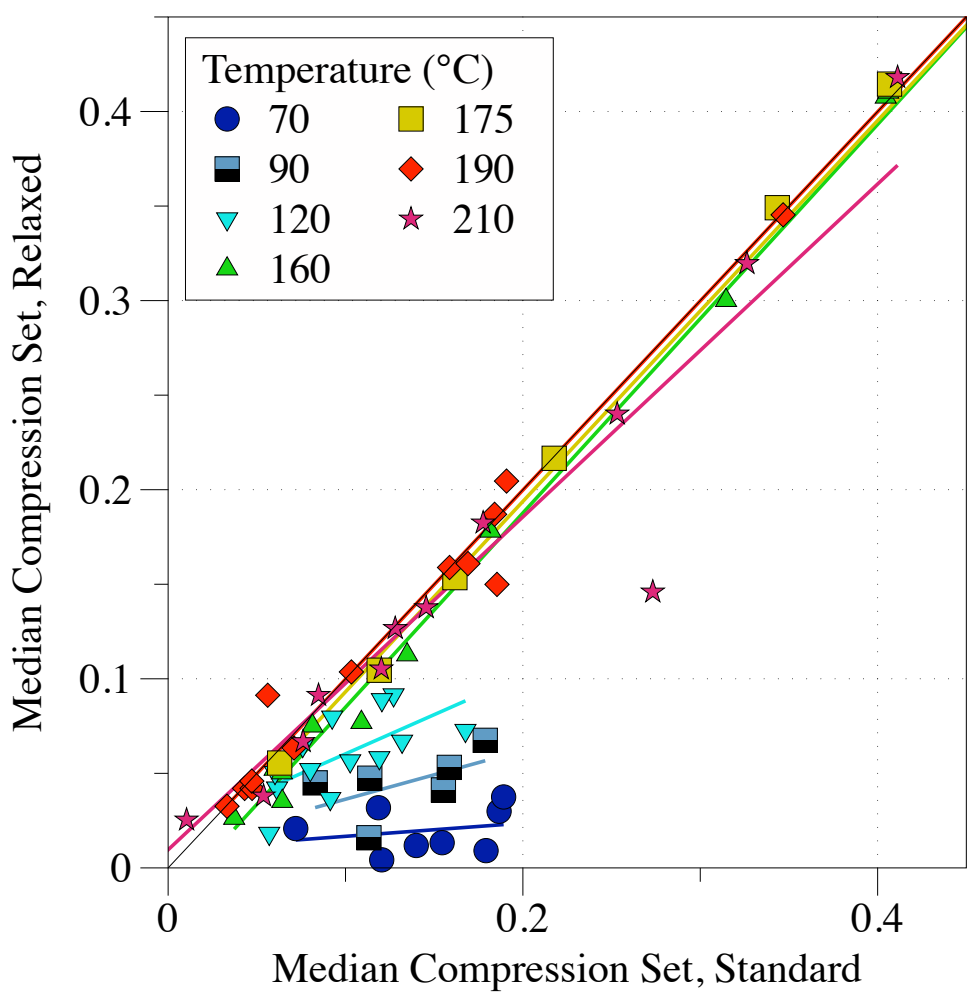

Figure 9. The median values of the standard compression set experiments versus the median values of the same experiments allowed to relax for a longer period of time. Each temperature series is shown with a trendline. Low temperature series have relaxed, but high temperature series have not.

In an effort to maximize the number of data points available to estimate a lifetime based on these accelerated aging experiments, we applied time-temperature superposition to a subset of the data 
in Figure $8 \mathrm{a}$ combined with a subset of the data in Figure 8b. Specifically, we used the relaxed compression set values (Figure $8 \mathrm{~b}$ ) from the low-temperature samples and the standard values (Figure 8a) from the high-temperature experiments. The validity of the subsequent analysis relies on the trends observed in Figure 9: the high-temperature samples do not relax, while the lowtemperature samples do. We then analyzed the merged data through time-temperature superposition.

In our process for determining shift factors, we first took the median values from each $70^{\circ} \mathrm{C}$ experiment on a plot of compression set versus aging time, and also plotted the medians of the $90^{\circ} \mathrm{C}$ data against shifted time. Starting with a shift factor of unity, we increased and decreased the value of the shift factor, causing the $90^{\circ} \mathrm{C}$ points to move back and forth in the $\mathrm{x}$-direction on the graph. We stopped making adjustments to the $90^{\circ} \mathrm{C}$ shift factor when the datapoints in the $90^{\circ} \mathrm{C}$ data appeared to be in alignment with the $70^{\circ} \mathrm{C}$ data, although the $90^{\circ} \mathrm{C}$ data may be seen to align with the lower temperature data over a relatively wide range of shift factors. We selected the value that placed the higher temperature data in about "the middle" of a plausible range. This process has, admitedly, more ambiguity in the value of the shift factors than we would like. This same process was repeated for the median values of the $120^{\circ} \mathrm{C}$ experiments, shifting them to align with the combined set of 70 and $90^{\circ} \mathrm{C}$ data, and then again with median values of the $160^{\circ} \mathrm{C}$ experiments to align them with the combined lower-temperature data. Since the $160^{\circ} \mathrm{C}$ data is the first series to show a pronounced change in compression set with time, there is a shorter range of shift factors over which the higher temperature experiment medians may be seen to align. Once the shift factors for each temperature series were established, a non-linear least squares fit of a power function was performed on the whole set of shifted medians.

The shift factors given in Table 3 were used with their respective compression set data series (median values) to generate the master curve shown in Figure 10. The lifetime can be estimated from the linear least squares fit of the master curve. Using the power function $a \times t^{b}$, we obtain values of $a=0.003 \pm 0.001$ and $b=0.35 \pm 0.04$ at the $95 \%$ confidence interval.

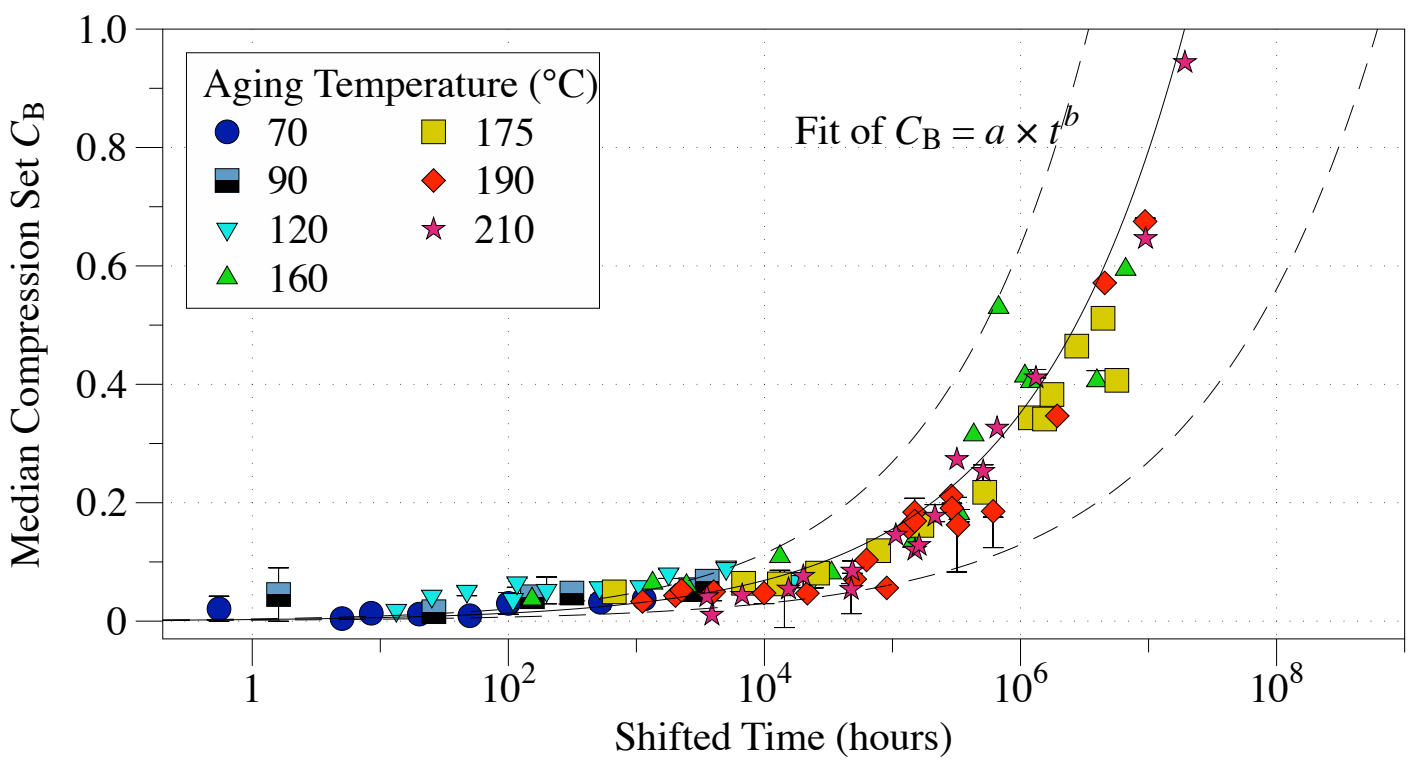

Figure 10. Compression set master curve, based on median values for each compression set experiment, with linear least squares regression line shown with $95 \%$ confidence bands for a fit of the form $a \times t^{b}$. 
The shift factors used to generate the curve in Figure 10 are given in Table 3 and plotted against inverse temperature in Figure 11. The shift factors do not show a linear relationship with inverse temperature over the whole temperature range. Instead, there seem to be two distinct regions. These two regions correlate with the differences observed in Figure 9. The high-temperature samples $\left(160-210^{\circ} \mathrm{C}\right)$ that maintained their compression set throughout the relaxation period fall into the "Region 1" area of Figure 11. The "Region 2" area is composed of the lowtemperature experiments $\left(70-120^{\circ} \mathrm{C}\right)$, in which the samples relaxed to a lower compression set value. In Region 1 the data is linear with a downward slope. Region 2 also has a downward slope but with a higher magnitude than that of Region 1. This type of non-Arrhenius behavior could result from two competing processes and has been observed in many polymer systems previously. ${ }^{14}$ In such cases, the simplest approach is to model the behavior as two competing reactions with individual activation energies.

Fitting the data in Region 1 (the high-temperature region) to a straight line yields a slope of approximately $-12613 \mathrm{~K}$; multiplying by the ideal gas constant $\mathrm{R}$ results in an activation energy of $105 \mathrm{~kJ} \mathrm{~mol}^{-1}$. This value is comparable to the value obtained by Salazar et al. on Viton of 151 $\mathrm{kJ} / \mathrm{mol}^{15}{ }^{15}$ In the high-temperature region, the slope is $-8562 \mathrm{~K}$, which gives an activation energy of $71 \mathrm{~kJ} / \mathrm{mol}$.

Table 3. Shift factors found by time-temperature superposition of Figure 10.

\begin{tabular}{r|ccccccc} 
Temperature $\left({ }^{\circ} \mathbf{C}\right)$ & $\mathbf{7 0}$ & $\mathbf{9 0}$ & $\mathbf{1 2 0}$ & $\mathbf{1 6 0}$ & $\mathbf{1 7 5}$ & $\mathbf{1 9 0}$ & $\mathbf{2 1 0}$ \\
\hline Shift Factor $\mathbf{a}_{\mathbf{T}}$ & 1 & 3 & 23 & 290 & 1180 & 1960 & 6700
\end{tabular}

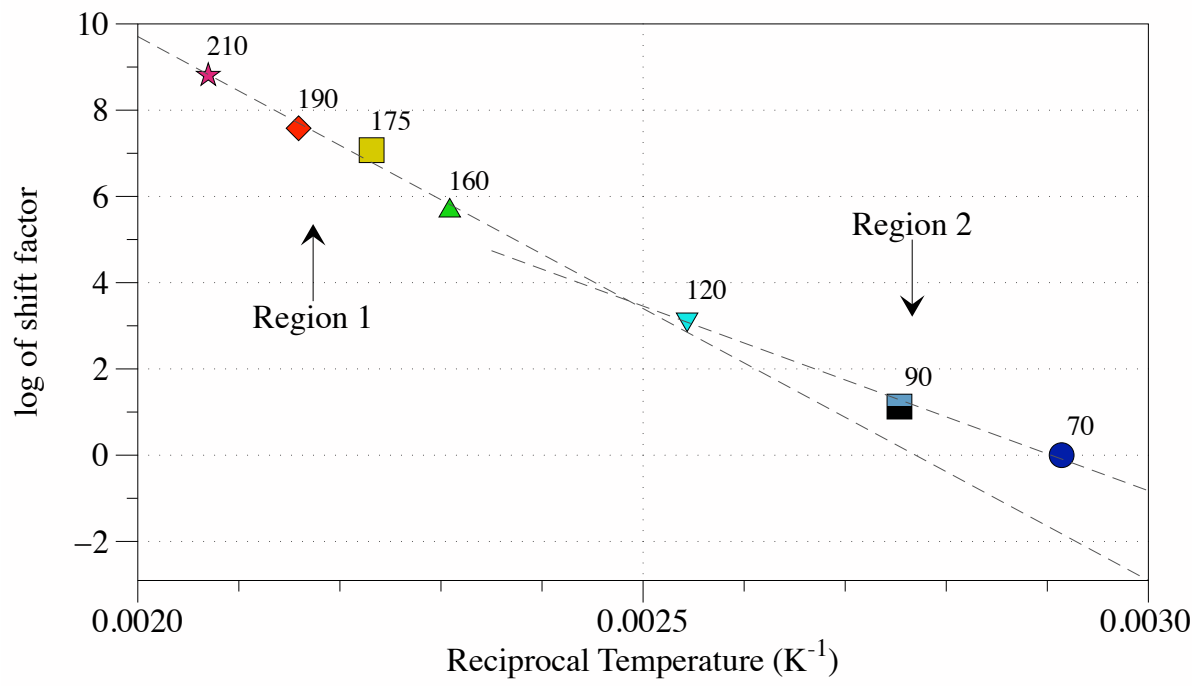

Figure 11. Arrhenius plot of the natural log of the shift factors $\left(a_{T}\right)$ versus reciprocal temperature for each temperature series of the experiment. The linear least squares regressions for the two regions are shown (dashed lines).

We can estimate the lifetime due only to the high-activation-energy process by extrapolating the linear fit of Region 1 to lower temperatures. For $70-120^{\circ} \mathrm{C}$, this results in $a_{\mathrm{T}}$ values ranging from $0.16-17.3$. This results in a lifetime at $80^{\circ} \mathrm{C}$ in the range of 267 to 39,675 years; the range represents the uncertainty in the master curve of Figure 10 at a compression set of $65 \%$. This analysis assumes that the energy of activation for the Region 1 irreversible reaction is 
independent of temperature in the range of $70-210^{\circ} \mathrm{C}$. To check this, we will conduct ultrasensitive oxygen consumption experiments in early FY17, which will provide insight into the chemical processes reflected by the two regions shown in Figure 11. This information will enable an improved lifetime prediction from the compression set measurements.

The master curve in Figure 10 from the time-temperature superposition is referenced to $70^{\circ} \mathrm{C}$, and it approximately captures the effect of both irreversible processes observed in Figure 11. It has the form

$$
C_{B}=a \times t^{b}
$$

The power function is used because it behaves similarly to the data over the range of the data. The original master curve is referenced to $70^{\circ} \mathrm{C}$ because that is the lowest temperature at which experiments were conducted. Formally, the reference temperature has a shift factor of 1 . To find the lifetime $t$ associated with a certain degree of compression set we use the expression:

$$
t=\left(\frac{C_{B}}{a}\right)^{\frac{1}{b}}
$$

The Williams-Landell-Ferry (WLF) equation can be used to translate predicted properties at the reference temperature $\left(T_{r}\right)$ into properties at another temperature $(T)$. It is essentially an interpolation between points on the Arrhenius plot to find the expected shift factor for an arbitrary temperature. A value on the master curve can then be translated backward in time, by dividing by $a_{\mathrm{T}}$, to make the new temperature have a shift factor equal to 1 .

$$
a_{T}=e^{\frac{-C_{1}\left(T-T_{r}\right)}{C_{2}+\left(T-T_{r}\right)}}
$$

Fitting the temperature and shift factor values at 70,90 , and $120^{\circ} \mathrm{C}$ for a reference temperature of $70^{\circ} \mathrm{C}$ yields WLF factors of $\mathrm{C}_{1}=-2578$ and $\mathrm{C}_{2}=40,860$. This gives an expected shift factor for $80^{\circ} \mathrm{C}$ of 1.88 .

Combining Equations 2 and 3 yields the expected time to reach a particular compression set (i.e., $65 \%$ ) at the new temperature (i.e., $80^{\circ} \mathrm{C}$ ).

$$
\begin{aligned}
t_{T} & =\left(\frac{C_{B}}{a}\right)^{\frac{1}{b}} / a_{T} \\
& =\left(\frac{0.65}{0.003}\right)^{\frac{1}{0.35}} / 1.88 \\
& =3,011,582 \text { hours } \sim 343 \text { years }
\end{aligned}
$$

Taking into consideration the uncertainty associated with the power function fit parameters $a$ and $b$ gives a lifetime in the range of 65 to 9647 years to attain $65 \%$ compression set at $80^{\circ} \mathrm{C}$. The lifetime estimated by this method is comparable to the estimate from the Region 1 extrapolation described in the previous paragraphs. Thus, the lifetime values estimated by the current analysis of the compression set data support an extension of the O-ring lifetime to 40 years.

Finally, the lifetime estimate from the accelerated aging compression set study can be compared to the compression set of O-rings in the field, for which the ages are known. The compression set of the O-rings used in the storage containers was estimated from a measurement of the O-ring thickness several weeks after removal from their containers as part of the SAVY-4000 surveillance program. The initial O-ring thickness was taken to be the average of 85 as-received O-rings: $5.333 \pm 0.045 \mathrm{~mm}$. The compressed thickness was taken to be the gland depth of the 
container, which was determined by finding the best value for the difference between the lid diameter and the collar diameter measured as part of the receipt inspection process. If receipt measurements were unavailable, the mean value for that particular size of container was taken from those surveyed in the receipt inspections. The final thickness measurement was taken by suspending the O-ring within the beam of a laser micrometer and averaging eight measurements at arbitrary positions around the O-ring. The uncertainty $\sigma$ varied with the precision of the values available for each calculation, but generally was in the range of 5-8\%. These values are graphed in Figure 12 along with the compression set data of Figure 8b. Figure 12 shows that the compression set of O-rings aged in the field for 0.8 to 4.9 years $(7000-43000$ hours $)$ is under $20 \%$; furthermore, these data follow the same trends exhibited by the low-temperature accelerated aging samples.

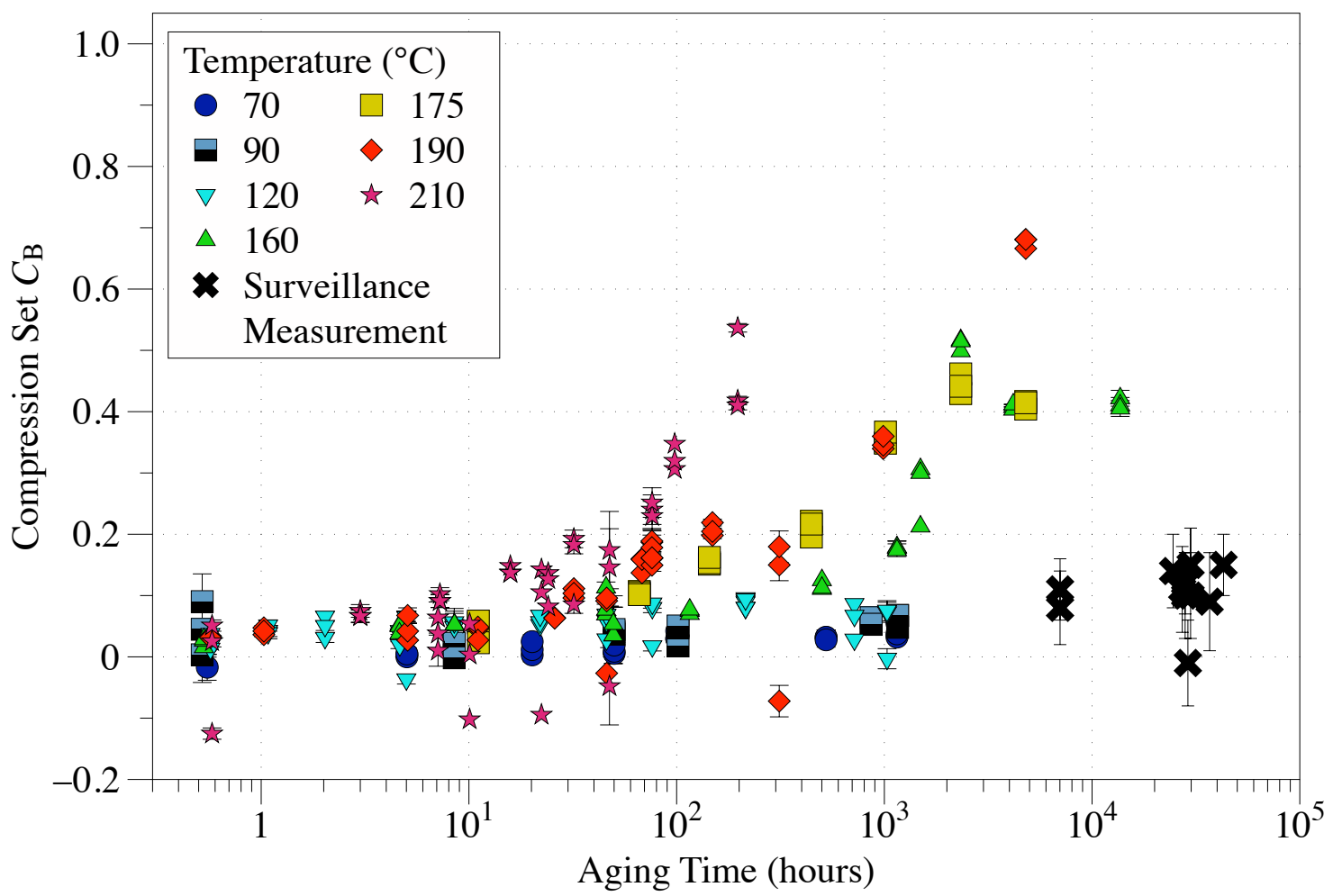

Figure 12. Plot of relaxed compression set data (all replicates shown) with the estimated compression set for O-rings analyzed under the SAVY-4000 Surveillance Program.

\subsubsection{Fourier-Transform Infrared Spectroscopy (FT-IR)}

FTIR measurements have been conducted on all of the aged samples, but no clear trends emerge based on aging treatment or the O-ring manufacturer's lot. A re-analysis of the collected spectra will be conducted in FY-17 to improve the statistical evaluation of this data, but there is no clear evidence of degradation at this time.

\subsubsection{Electron Paramagnetic Resonance (EPR)}

We have previously measured EPR at low temperatures $(5 \mathrm{~K})$ to avoid the influence of iron compounds in the sample. However, Figure 13 shows that, at room temperature, the EPR 
lineshape changes radically between a pristine sample and one that has been annealed at $210^{\circ} \mathrm{C}$. Thus, we conducted a study to compare this lineshape for unaged vs. thermally aged (at 70, 90, 120 , and $160^{\circ} \mathrm{C}$, all under compression) O-ring samples. The results for the aged samples are summarized in Figure 14. These spectra have been normalized so that the resonance shapes can be more easily compared, as previous research ${ }^{16}$ has shown that the EPR linewidth (not intensity) is indicative of iron hydroxide changes. This initial view indicates that the EPR lineshape does change for samples aged at 120 and $160^{\circ} \mathrm{C}$, but Figure 15 shows that the unaged baseline curves (in black) have the same shapes as their respective thermally aged samples (red curves). Further investigation reveals that the 70 and $90^{\circ} \mathrm{C}$ samples were obtained from the same material lot, while the $120^{\circ} \mathrm{C}$ samples were derived from a different lot and the $160^{\circ} \mathrm{C}$ samples were derived from two different lots. For the samples measured to date, the changes in the EPR lineshape appear to be dependent on the material lot and are not related to the aging temperature or time. In the near future, we will also measure EPR spectra of samples aged at higher temperatures to determine if all of the lineshape variation is material lot dependent.

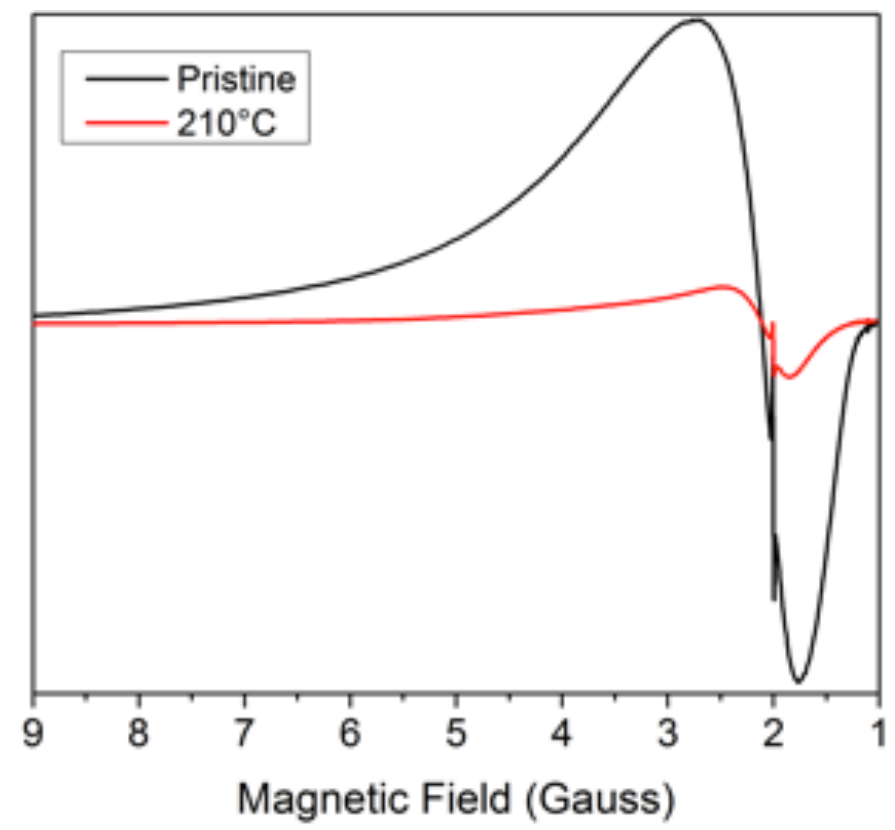

Figure 13. Change in EPR lineshape upon annealing a sample to $210^{\circ} \mathrm{C}$. 


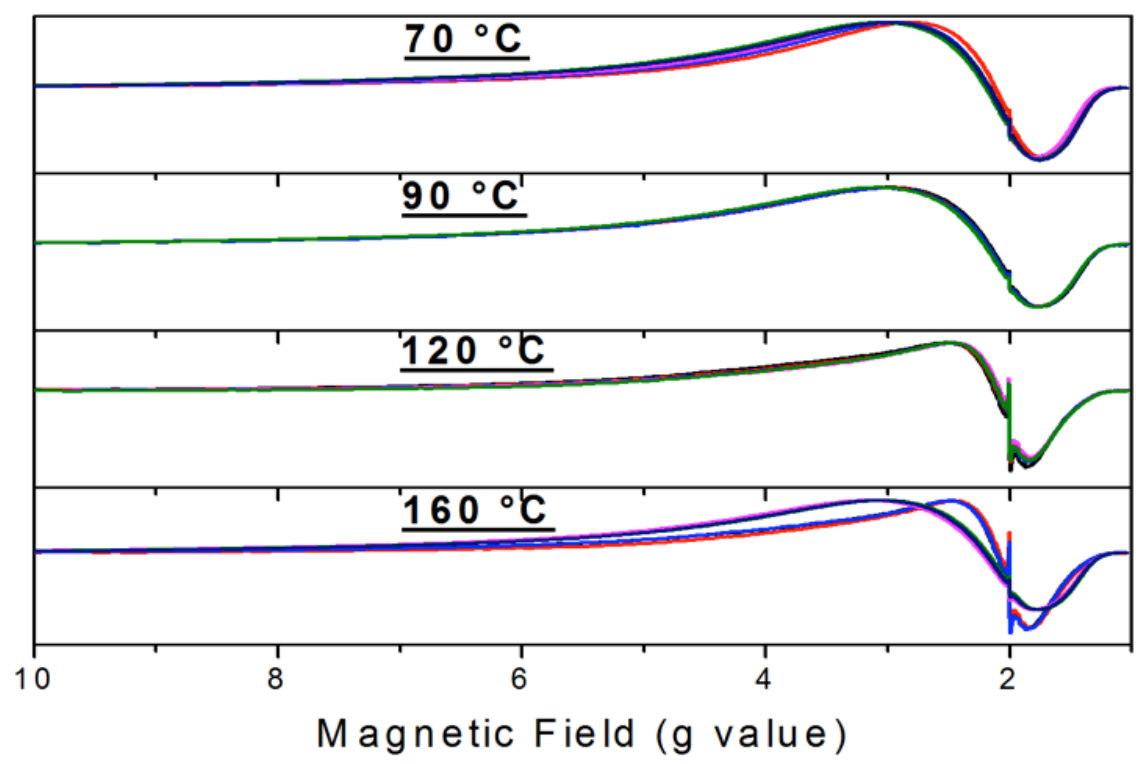

Figure 14. Normalized EPR spectra, measured at room temperature, of SAVY-4000 samples aged at the indicated temperatures.
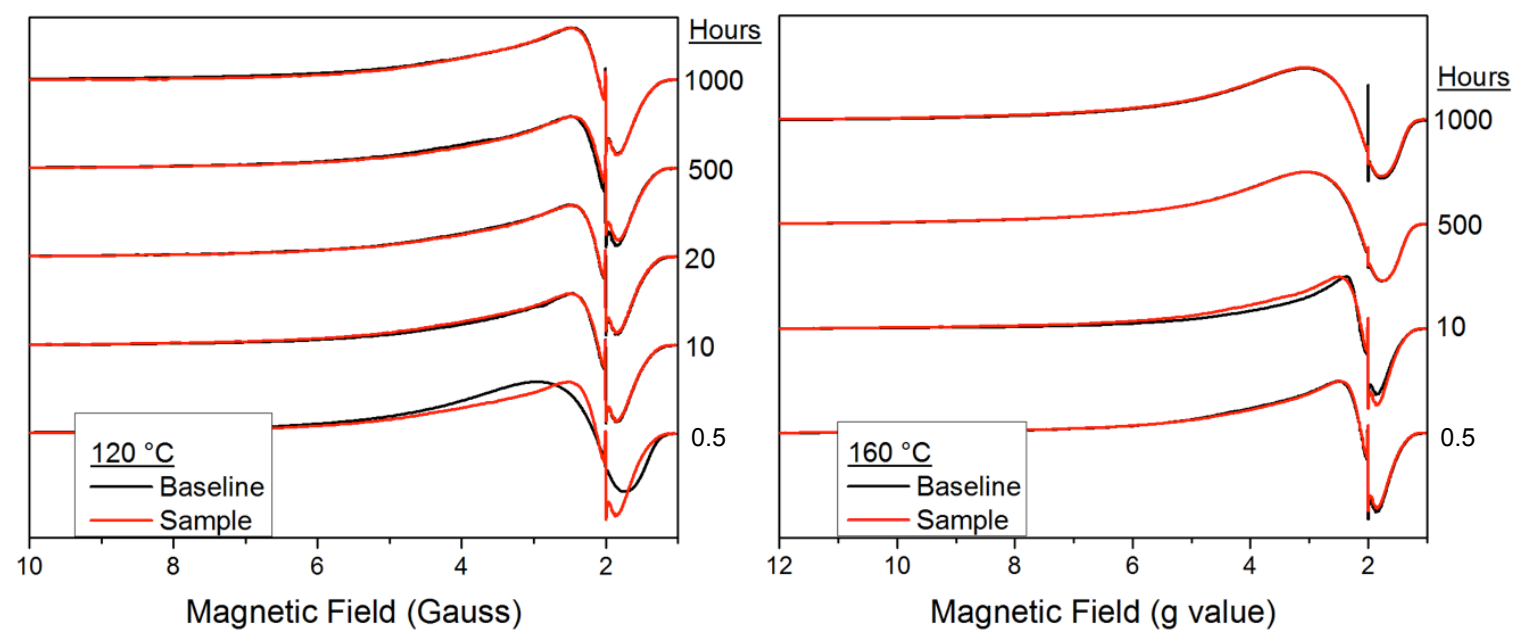

Figure 15. Normalized EPR spectra for SAVY-4000 samples aged at 120 (left) and $160^{\circ} \mathrm{C}$ (right), along with the corresponding baseline samples. The aging hours are indicated on the right side of the graph.

\subsubsection{Differential Scanning Calorimetry (DSC)}

Differential Scanning Calorimetry experiments were conducted for a wide range of unaged and thermally aged (under compression) O-ring samples. In general, two types of transitions were observed, as shown in Figure 16a. The first was an endothermic transition, generally occurring in the range of $100-200^{\circ} \mathrm{C}$; the second was an exothermic transition that began at temperatures above $220^{\circ} \mathrm{C}$. Traces for individual samples can be split into 4 groups: (1) both endotherm and exotherm; (2) endotherm only; (3) exotherm only; (4) no transitions. In all cases, any observed transitions only occurred during the first heating cycle but not during the subsequent cooling or second heating. This suggests that these transitions are irreversible. Unfortunately, there was no clear trend between the existence of these transitions and aging time or temperature. For 
example, Figure $16 \mathrm{~b}$ shows that all 3 replicates of the sample aged at $70^{\circ} \mathrm{C}$ for $5 \mathrm{hrs}$ exhibited both endotherms and exotherms, while the unaged control piece showed neither. However, Figure 16c shows that the unaged control and 1 replicate of the sample aged at $70^{\circ} \mathrm{C}$ for $500 \mathrm{hrs}$ have both exotherms and endotherms, one aged replicate has an exotherm only, one aged replicate has neither. Note that the unaged samples in Figures 16b and 16c come from the same lot; one has both transitions and the other has neither. Several more examples of the inconsistencies seen in the DSC data are shown in Figures 16d - 16f. Overall, the inconsistent nature of these results suggests at least two different possible explanations. First, trace amounts of chemicals present in the O-rings may undergo an exothermic reaction at temperatures above $220^{\circ} \mathrm{C}$. However, such trace amounts are not expected to affect O-ring lifetime at the maxium allowed usage temperature of $80^{\circ} \mathrm{C}$. Second, the time scale of the DSC experiment (order of minutes) may be insufficient for the consistent observation of reactions associated with the polymer (e.g., chain scission or crosslinking).

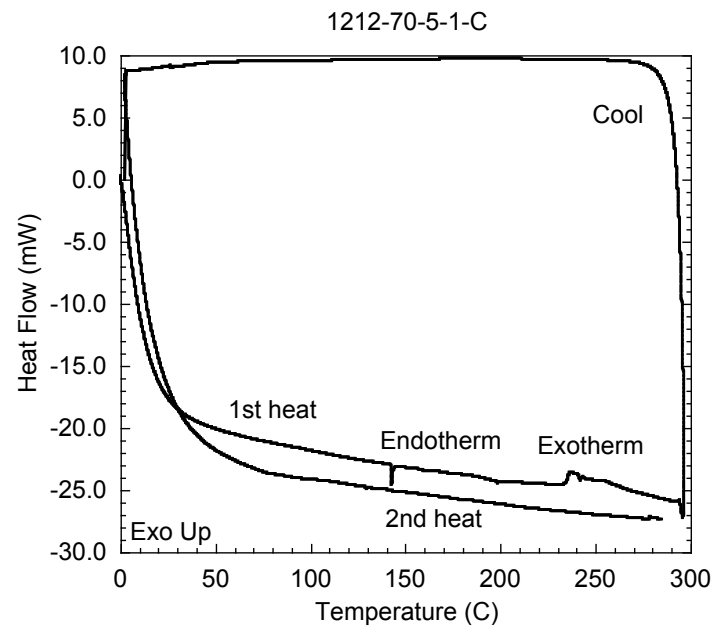

(a)

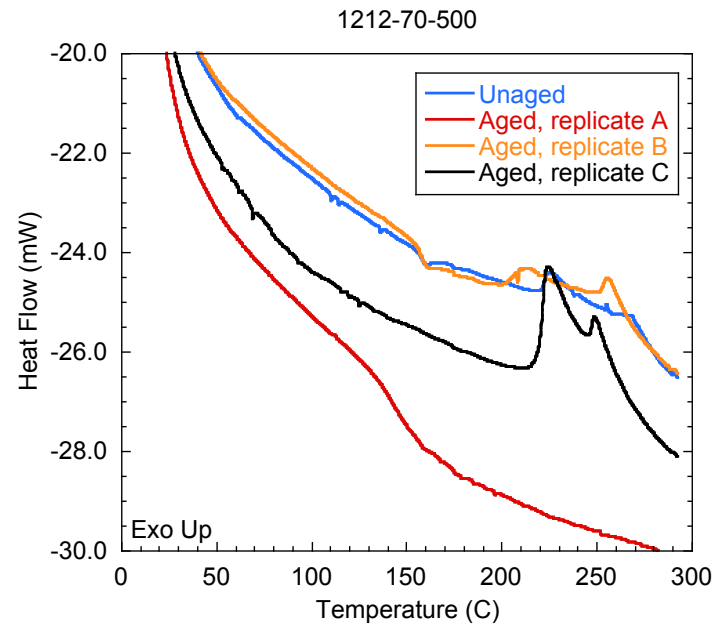

(c)

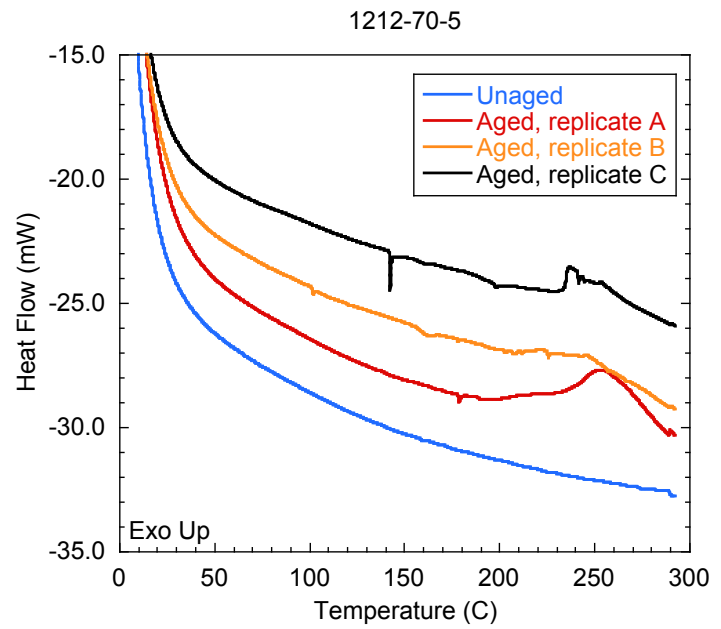

(b)

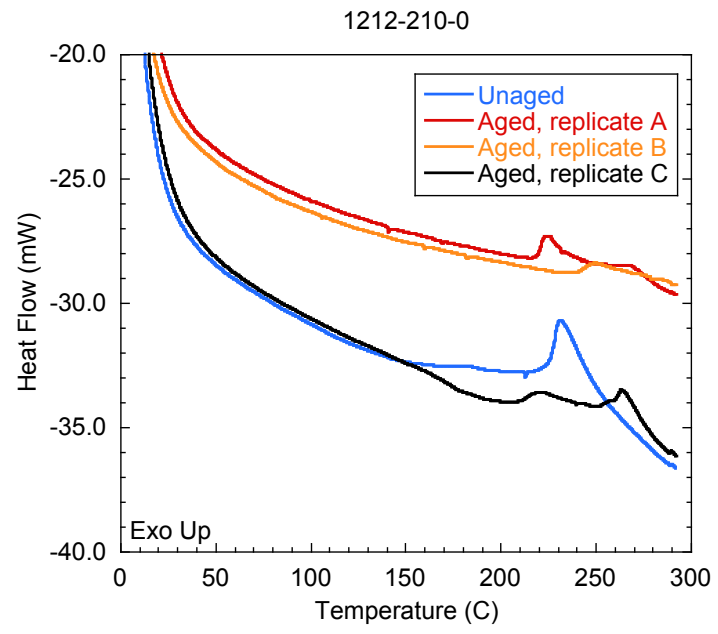

(d) 


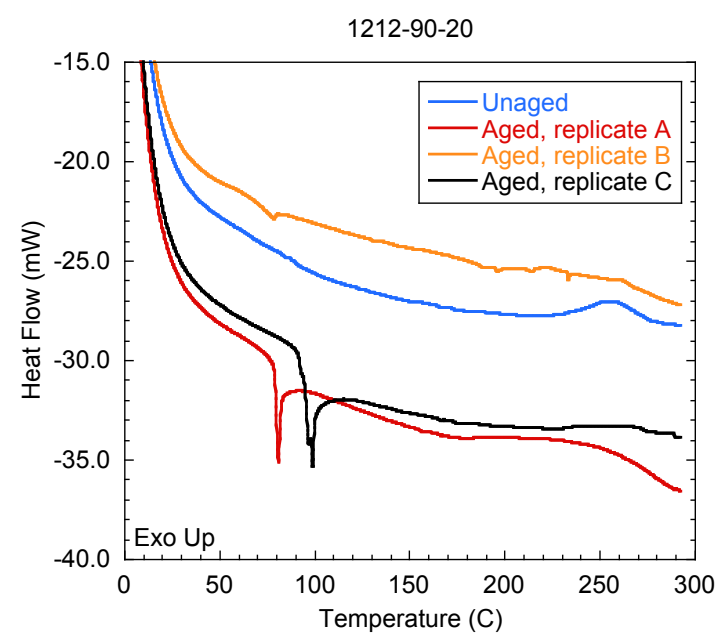

(e)

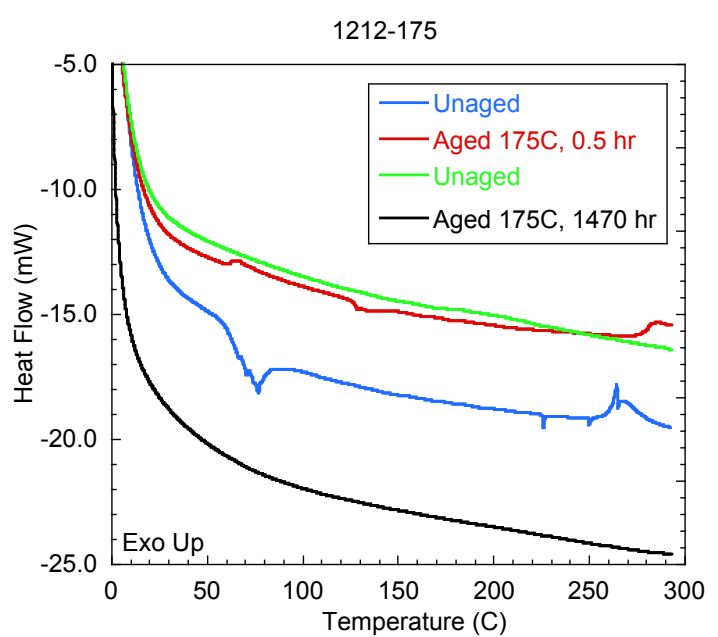

(f)

Figure 16. DSC traces for unaged and thermally aged O-ring sample pieces. (a) An example showing that both endotherm and exotherm are observed only during the first heating, while no transitions can be seen upon cooling or the second heating. (b) - (f) Examples showing the inconsistent nature of the DSC results (first heating only).

\subsubsection{Gel-Permeation Chromatography (GPC)}

Gel-permeation chromatography experiments were carried out on unaged and selected thermally aged samples from the compression set experiments. These samples were soaked in a solvent to extract any linear / uncrosslinked chains. If a significant amount of chain scission is occurring due to thermal aging, the GPC measurements on the extracts should detect an increase in the concentration of linear chains. Figure 17 shows the GPC traces from extracts of an O-ring sample that had been aged for 1000 hours at $210^{\circ} \mathrm{C}$, along with its unaged control sample. Peaks with retention time near 14 min represent uncrosslinked or degraded polymeric species, while those with retention times greater than $18 \mathrm{~min}$ are due to small molecules and solvent. The inset of each plot shows an enlargement of the traces in the range of $8-16 \mathrm{~min}$, with the scale of the concentration axis held constant between the two insets. The aged sample shows larger peaks due to uncrosslinked / degraded polymer than the unaged one, suggesting that chain scission is occurring in the sample aged at $210^{\circ} \mathrm{C}$ for 1000 hours. Similar GPC experiments were repeated on several other aged samples with low aging temperature or short times, including the following aging temperature / time combinations: $70^{\circ} \mathrm{C}$ for $5 \mathrm{hr}, 70^{\circ} \mathrm{C}$ for $500 \mathrm{hr}, 90^{\circ} \mathrm{C}$ for $20 \mathrm{hr}, 120^{\circ} \mathrm{C}$ for $10 \mathrm{hr}, 175^{\circ} \mathrm{C}$ for $0.5 \mathrm{hr}, 190^{\circ} \mathrm{C}$ for $1 \mathrm{hr}$, and $210^{\circ} \mathrm{C}$ for $0.5 \mathrm{hr}$. None of these show the presence of degradation products. These limited results suggest that the chemical degradation mechanism produces a measureable amount of degraded polymer for the sample aged at high temperature for a long time, but no measurable degradation products for samples aged at low temperatures or short times. Further GPC measurements will be made for additional aged samples (along with their unaged counterparts) in FY17 to probe the validity of this apparent trend and to quantify it. 

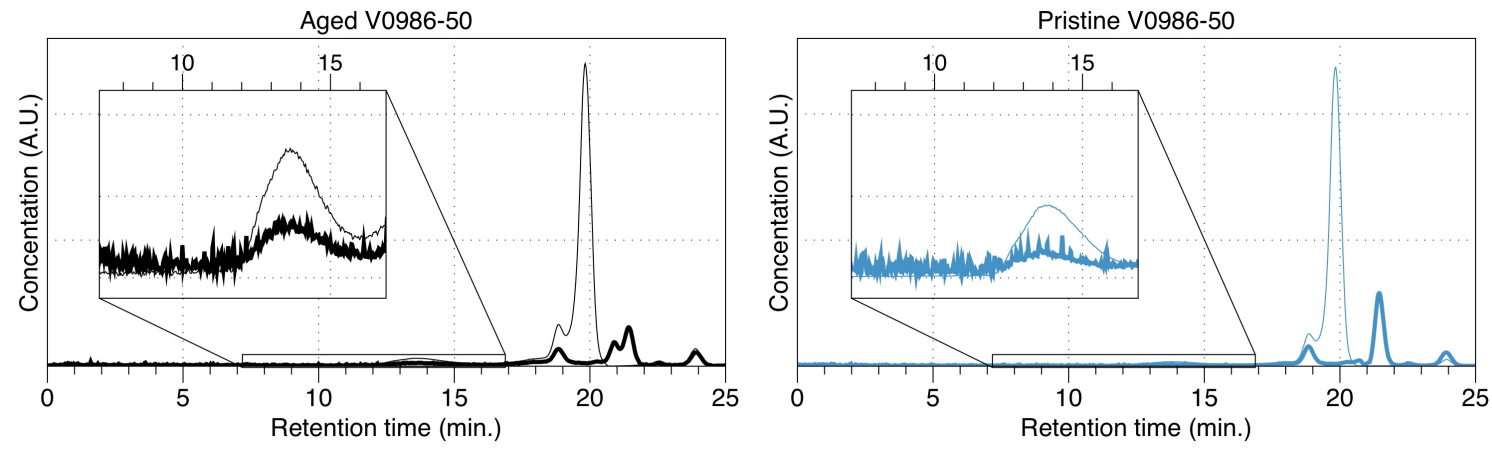

Figure 17. GPC traces from O-ring segment extracts. Thick line represents initial extraction (room temperature, 3 days) in THF. Thin line represents extraction after an additional 5 hours in THF at $50^{\circ} \mathrm{C}$. 


\section{Discussion, Conclusions, and Future Work}

The data from the O-ring compression set experiments suggest that as many as three aging mechanisms are at play during our accelerated aging experiments: a reversible one and two irreversible ones. Using various characterization techniques on aged samples, we have only been able to detect chemical degradation at the highest aging temperatures and longest aging times. However, the accelerated aging methods used thus far cannot distinguish between chemical and physical mechanisms. Furthermore, the high-activation-energy process, probably a chemical mechanism, likely occurs very slowly at lower temperatures (e.g., $70-120^{\circ} \mathrm{C}$ ), which is consistent with the very nature of a high activation energy process.

To separate the effect of the reversible aging mechanism from the irreversible ones, we measured compression set after allowing the aged O-rings to physically relax for long periods of time. Compression set was reduced for samples aged at low temperatures $\left(70-120^{\circ} \mathrm{C}\right)$, while at high aging temperatures $\left(160-210^{\circ} \mathrm{C}\right)$ compression set was maintained. After performing timetemperature superposition, we used two methods to estimate ranges for the lifetime at $80^{\circ} \mathrm{C}$. The failure point of the compression set was chosen as $65 \%$ to reflect the results of the wholecontainer aging experiments. The first method uses the high-temperature shift factors employed in the time-temperature superposition analysis to back-calculate new shift factors for the low temperature region $\left(70-90^{\circ} \mathrm{C}\right)$. In this way, we obtain a lifetime due to the high-activationenergy process only. Using these new shift factors, we estimate a lifetime range of 267 to 39,675 years at $80^{\circ} \mathrm{C}$. The second method approximates the combined effect of both irreversible processes to give a lifetime in the range of 65 to 9647 years at $80^{\circ} \mathrm{C}$, and this is the best estimate based on the results obtained to date.

Aged O-ring samples have been characterized by various methods to probe the chemical and physical aging mechanisms, but more data is needed to sort out the complex nature of the polymer aging process. ${ }^{17,18}$ Possible chemical mechanisms include reaction of the polymer with the catalyst and / or other additives in the O-ring. Oxidation of the polymer may also be occurring, and this process may be affected by the diffusion rate of oxygen into the O-ring.

Our results fully support the proposed lifetime extension for the O-rings at $80^{\circ} \mathrm{C}$ to 40 years. Because we do not fully understand the chemical degradation mechanisms, we will continue probing them over the next 6 months in order to identify the mechanism that results in the shortest lifetime. The primary tool that we will use is a set of ultrasensitive oxygen consumption measurements to be completed by Feb 2017. With these experiments, we should be able to detect minute levels of oxidation, if it is occurring, in samples aged at low temperatures. 


\section{References}

1) DOE, "Nuclear Material Packaging Manual". DOE M 441.1-1, https://www.directives.doe.gov/directives/current-directives/441.1-DManual-1/view

2) Smith, P.H., Stone, T.A., Veirs, D.K., Anderson, L.L., Blair, M.W., Hamilton, J., Kelly, E., Moore, M.E., Teague, J.G., Weis, E., and Yarbro, T.F., DOE/NNSA review, "Safety analysis report for the SAVY 4000 container series," (2012).

3) Gladson, J., and Hagan, R., "Nuclear Material Container Testing," Los Alamos National Laboratory. (1999).

4) Gladson, J., and Hagan, R., "Nuclear Material Container Testing," Los Alamos National Laboratory. (1999).

5) Weis, E.M., Blair, M.W., Hill, B.D., Stone, T.A., Smith, P.H., Winter, J.C., Reeves, K.P., and Veirs, D.K., "Durability and field condition study of seal of SAVY-4000 storage container." (2014), Packaging, Transport, Storage \& Security of Radioactive Material 25(1): 24-9. 10.1179/1746510914y.0000000059

6) Blair, M.W., Weis, E., Veirs, D.K., Smith, P.H., Stone, T.A., and Ball, J.M., Service Life Prediction of Polymeric Materials: Vision for the Future ; 2013-03-03 - 2013-03-08 ; Monterrey, California, United States, "Accelerated Aging Studies for the Lifetime Extension of O-rings Used in the SAVY-4000 Unit," (2013).

7) ASTM International. Standard Test Methods for Rubber Property - Compression Set; ASTM D 395 03; 2008; Vol. 9.

8) ASTM International. Standard Test Method for Rubber Property — Durometer Hardness. Annual Book of ASTM Standards, 2010, D2240 - 5, 1-13.

9) Hanson, B. A. ChemoSpec, 2015.

10) Frisch, M. J.; Trucks, G. W.; Schlegel, H. B.; Scuseria, G. E.; Robb, M. A.; Cheeseman, J. R.; Scalmani, G.; Barone, V.; Mennucci, B.; Petersson, G. A.; Nakatsuji, H.; Caricato, M.; Li, X.; Hratchian, H. P.; Izmaylov, A. F.; Bloino, J.; Zheng, G.; Sonnenberg, J. L.; Hada, M.; Ehara, M.; Toyota, K.; Fukuda, R.; Hasegawa, J.; Ishida, M.; Nakajima, T.; Honda, Y.; Kitao, O.; Nakai, H.; Vreven, T.; Montgomery Jr., J. A.; Peralta, J. E.; Ogliaro, F.; Bearpark, M.; Heyd, J. J.; Brothers, E.; Kudin, K. N.; Staroverov, V. N.; Kobayashi, R.; Norm, J.; Raghavachari, K.; Rendell, A.; Burant, J. C.; Iyengar, S. S.; Tomasi, J.; Cossi, M.; Rega, N.; Millam, J. M.; Klene, M.; Knox, J. E.; Cross, J. B.; Bakken, V.; Adamo, C.; Jaramillo, J.; Gomperts, R.; Stratmann, R. E.; Yazyev, O.; Austin, A. J.; Cammi, R.; Pomelli, C.; Ochterski, J. W.; Martin, R. L.; Morokuma, K.; Zakrzewski, V. G.; Voth, G. A.; Salvador, P.; Dannenberg, J. J.; Dapprich, S.; Daniels, A. D.; Farkas, Ö.; Foresman, J. B.; Ortiz, J. V.; Cioslowski, J.; Fox, D. J. Gaussian 09, Revision B.01, 2009.

11) Twum, E. B.; McCord, E. F.; Fox, P. A.; Lyons, D. F.; Rinaldi, P. L. Macromolecules 2013, 46, 4892.

12) Pianca, M.; Bonardelli, P.; Tatò, M.; Cirillo, G.; Moggi, G. Polymer (Guildf). 1987, 28, 224.

13) Monti, G. A.; Harris, R. K. Magn. Reson. Chem. 1998, 36, 892

14) Celina, M.; Gillen, K. T.; Assink, R. A. Polym. Degrad. Stab. 2005, 90, 395.

15) Salazar, E. A.; Curro, J. G.; Gillen, K. T. J. Appl. Polym. Sci. 1977, 21, 1597.

16) Blair, M.W.; Muenchausen, R.E.; Taylor, R.D.; Bennett, B.L.; Labouriau, A.; Stephens, T.S.; Smith, J.F.; Cooke, D.W. Polym. Degrad. Stab. 2008, 93, 1585.

17) Gillen, K.T.; Celina, M.; Clough, R.L.; Wise, J. Trends Polym. Sci. 1997, 5, 250.

18) Gillen, K.T.; Bernstein, R.; Celina, M. Rubber Chem. Technol. 2015, 88, 1. 